\title{
The effect of fatty acid surfactants on the uptake of nitric acid to deliquesced $\mathrm{NaCl}$ aerosol
}

\author{
K. Stemmler ${ }^{1}$, A. Vlasenko ${ }^{1, *}$, C. Guimbaud ${ }^{1, * *}$, and M. Ammann ${ }^{1}$ \\ ${ }^{1}$ Laboratory of Radio- and Environmental Chemistry, Paul Scherrer Institute, 5232 Villigen, Switzerland \\ * now at: Department of Chemistry and Southern Ontario Centre for Atmospheric Aerosol Research, University of Toronto, 80 \\ St. George Street, Toronto M5S 3H6, Ontario, Canada \\ ** now at: Laboratoire de Physique et Chimie de l'Environnement, CNRS, Université d'Orléans 45071 Orléans \\ Cedex 2, France
}

Received: 4 December 2007 - Published in Atmos. Chem. Phys. Discuss.: 11 January 2008

Revised: 22 July 2008 - Accepted: 5 August 2008 - Published: 2 September 2008

\begin{abstract}
Surface active organic compounds have been observed in marine boundary layer aerosol. Here, we investigate the effect such surfactants have on the uptake of nitric acid $\left(\mathrm{HNO}_{3}\right)$, an important removal reaction of nitrogen oxides in the marine boundary layer. The uptake of gaseous $\mathrm{HNO}_{3}$ on deliquesced $\mathrm{NaCl}$ aerosol was measured in a flow reactor using $\mathrm{HNO}_{3}$ labelled with the short-lived radioactive isotope ${ }^{13} \mathrm{~N}$. The uptake coefficient $\gamma$ on pure deliquesced $\mathrm{NaCl}$ aerosol was $\gamma=0.5 \pm 0.2$ at $60 \%$ relative humidity and $30 \mathrm{ppb} \mathrm{HNO}_{3}(\mathrm{~g})$. The uptake coefficient was reduced by a factor of 5-50 when the aerosol was coated with saturated linear fatty acids with carbon chain lengths of 18 and 15 atoms in monolayer quantities. In contrast, neither shorter saturated linear fatty acids with 12 and 9 carbon atoms, nor coatings with the unsaturated oleic acid (C18, cisdouble bond) had a detectable effect on the rate of $\mathrm{HNO}_{3}$ uptake. It is concluded that it is the structure of the monolayers formed, which determines their resistance towards $\mathrm{HNO}_{3}$ uptake. Fatty acids (C18 and C15), which form a highly ordered film in the so-called liquid condensed state, represent a significant barrier towards $\mathrm{HNO}_{3}$ uptake, while monolayers of shorter-chain fatty acids $(\mathrm{C} 9, \mathrm{C} 12)$ and of the unsaturated oleic acid form a less ordered film in the liquid expanded state and do not hinder the uptake. Similarly, high contents of humic acids in the aerosol, a structurally inhomogeneous, quite water soluble mixture of oxidised high molecular weight organic compounds did not affect $\mathrm{HNO}_{3}$ uptake. As surfactant films on naturally occurring aerosol
\end{abstract}

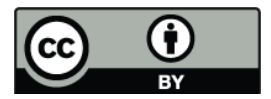

Correspondence to: M. Ammann (markus.ammann@psi.ch) are expected to be less structured due to their chemical inhomogeneity, it is likely that their inhibitory effect on $\mathrm{HNO}_{3}$ uptake is smaller than that observed here for the $\mathrm{C} 15$ and $\mathrm{C} 18$ fatty acid monolayers.

\section{Introduction}

In this study, we address the effects of fatty acid films and of water soluble organic aerosol constituents on the uptake of atmospheric nitric acid $\left(\mathrm{HNO}_{3}\right)$ to deliquesced $\mathrm{NaCl}$ aerosol through (R1).

$\mathrm{HNO}_{3}(\mathrm{~g})+\mathrm{NaCl}(\mathrm{aq}) \rightarrow \mathrm{NaNO}_{3}(\mathrm{aq})+\mathrm{HCl}(\mathrm{g})$

$\mathrm{HNO}_{3}$ is the end product of the atmospheric oxidation of nitrogen oxides $\left(\mathrm{NO}_{\mathrm{x}}\right)$ and a major acidifying species in the troposphere. Heterogeneous loss to sea-salt aerosol has been suggested to play an important role in the removal pathway of nitric acid in the marine troposphere via the aciddisplacement (R1) (Spokes et al., 2000; Gard et al., 1998; Brimblecombe and Clegg, 1988).

Under many conditions in the marine troposphere, sea-salt aerosol is present in the form of deliquesced aerosol particles. However, the majority of laboratory experiments dealing with the $\mathrm{HNO}_{3}$ sea-salt interaction have mainly provided kinetic information for solid $\mathrm{NaCl}$ exposed to $\mathrm{HNO}_{3}$ (Rossi, 2003). The measured uptake was found to be strongly dependent on the humidity (Ghosal and Hemminger, 2004; Davies and Cox, 1998; Beichert and Finlayson-Pitts, 1996; Rossi, 2003).

Published by Copernicus Publications on behalf of the European Geosciences Union. 
The investigations performed with deliquesced sea salt aerosol (Liu et al., 2007; Abbatt and Waschewsky, 1998; Guimbaud et al., 2002; ten Brink, 1998; Tolocka et al., 2004; Saul et al., 2006) generally show a very high reactivity of the aerosol towards $\mathrm{HNO}_{3}$.

Organic compounds represent a significant percentage of the composition of atmospheric aerosols. Even in marine sea salt aerosol, organics may represent a large fraction of the composition; up to $60 \%$ of the dry mass may be organic components (Cavalli et al., 2004; Middlebrook et al., 1998; O'Dowd et al., 2004). Amphiphilic organics (surfactants) are a significant fraction of the organic content found in atmospheric aerosol samples (Latif and Brimblecombe, 2004; Alves et al., 2002; Barger and Garrett, 1976; Fraser et al., 2003; Mochida et al., 2003; Blanchard, 1964). Surfactants are molecules that contain two regions with different polarities, hydrophobic tails, and hydrophilic head groups, resulting in an innate ability to partition to an aqueous interface where they can form a self-assembled film (a monolayer). Recent experimental work has verified the prediction that marine sea salt aerosol could have an exterior film of surfactants; palmitic, stearic and oleic acids were found predominantly (Tervahattu et al., 2002; Mochida et al., 2002). The oceans are a physically large source of sea salt aerosol particles produced at the unsettled sea surface, where wind and waves create bursting bubbles ejecting fine droplets of surface ocean water into the marine boundary layer (Ellison et al., 1999; Sicre et al., 1990; Blanchard, 1964). Marine aerosols formed by this sea spray have an aqueous, saline core but could carry an organic surface layer consisting of organic material accumulated at the sea surface. During a cruise on the eastern Mediterranean, Red Sea and Indian Ocean, Romano (Romano, 1996) reported that thick, visible organic layers covered about $30 \%$ of the coastal waters and $11 \%$ of the open sea. This organic material originates from decomposition of marine biota.

Surfactant layers are shown to concentrate, orient, select, and stabilize certain surfactant molecules while equilibrating (Gilman et al., 2004). Therefore, the coating is called self-assembling. The occurrence, structures and atmospheric implications of organic films on aerosols have been reviewed initially by Gill et al. (1983) and most recently by Donaldson and Vaida (2006). The atmospheric roles and structures of fatty acid monolayers have been specifically reviewed by Seidl (2000).

Besides organic substances originating from marine biota, also terrestrial biogenic and anthropogenic organic compounds partition to pre-existing particles or form new particles (Secondary Organic Aerosol, SOA). Many of these organics are degradation products of the atmospheric oxidation of Volatile Organic Compounds (VOC). Field studies (Zappoli et al., 1999; Gelencser et al., 2000; Krivacsy et al., 2000; Cappiello et al., 2003) and laboratory studies showed that such oxygenated VOC's do only partly persist there as monomeric structures, but tend to form higher molar weight oligomers or humic-like complex structures (Jang et al., 2003; Jang et al., 2002; Kalberer et al., 2004; Nozière and Esteve, 2005; Gelencser et al., 2003), which may also have the ability to partition to the surface of mixed organic inorganic particles.

Surfaces of organic aerosols interact with gas phase oxidants and radicals, as well as with additional organic and inorganic (like atmospheric water vapour) atmospheric species (Rudich, 2003). Therefore, the chemical and physical properties of the surface will determine to a large extent the environmental roles played by particles. Organic surface layers on aqueous aerosol can have a strong impact on the phase transfer kinetics of atmospheric chemicals and hence can influence the rate of heterogeneous reactions. Fatty acid coatings have been shown to alter the deliquescence rates of purely inorganic core particles and possibly affect the equilibrium uptake of water (Xiong et al., 1998; Hansson et al., 1998). Such coatings have the potential to decrease the kinetic flux of water vapor to the aqueous phase during the process of CCN formation and growth (Chuang, 2003).

A number of recent studies have addressed the effects of organic coatings on the phase transfer of atmospherically relevant molecules (Däumer et al., 1992; Jefferson et al., 1997; Folkers et al., 2003; Thornton and Abbatt, 2005; Glass et al., 2006; Gilman and Vaida, 2006; McNeill et al., 2006; Park et al., 2007; Clifford et al., 2007; Cosman et al., 2008). The observed effects different surfactants have vary substantially and depend on the substrate, the monolayer properties and also on the type of trace gas and its sink process in the condensed phase. The results suggest that therefore many heterogeneous atmospheric processes may depend on detailed structural features of mixed organic/inorganic particles.

In this study, we investigate the effect of $\mathrm{C} 9$ to $\mathrm{C} 18$ fatty acids and of humic acid to the uptake of $\mathrm{HNO}_{3}$ to deliquesced $\mathrm{NaCl}$ aerosol particles. The observed reduction of the uptake coefficient is related to the monolayer forming properties of the fatty acids used.

\section{Experimental}

The experimental techniques employed here are similar to those reported previously (Ammann, 2001; Kalberer et al., 1999; Guimbaud et al., 2002; Vlasenko et al., 2005; Vlasenko et al., 2006). Nitrogen oxides labelled with the short-lived radioactive isotope ${ }^{13} \mathrm{~N}$ are mixed with the aerosol particles in a $0.8 \mathrm{~cm}$ i.d. PTFE flow tube reactor. Gasphase and particulate products are trapped downstream of the reactor in selectively coated denuders and in a particulate filter, respectively. The concentration of each gaseous and particulate species is calculated by counting the number of decays of ${ }^{13} \mathrm{~N}$ in each trap and using a simple data inversion similar to that used by Rogak et al. (1991). The experimental procedure to generate $\mathrm{HNO}_{3}$ and the mixed organic- $\mathrm{NaCl}$ particles is described hereafter. 


\subsection{Production of labelled $\mathrm{HNO}_{3}$}

The procedure to provide the radioactive isotope ${ }^{13} \mathrm{~N}$ $\left(\tau_{1 / 2}=10 \mathrm{~min}\right)$ in the form of ${ }^{13} \mathrm{NO}$ in a flow of $20 \% \mathrm{O}_{2}$ in $\mathrm{He}$ as carrier gas has been described in detail elsewhere (Ammann, 2001; Guimbaud et al., 2002; Vlasenko et al., 2006). In the laboratory a small fraction of this ${ }^{13} \mathrm{NO}$ was mixed with the buffer gas ( 1 slpm of $\mathrm{N}_{2}$ ), and a large excess of ${ }^{14} \mathrm{NO}$ (i.e. NO containing the stable isotope of nitrogen ${ }^{14} \mathrm{~N}$, for simplicity we refer to ${ }^{14} \mathrm{~N}$ as $\mathrm{N}$ later on) was added from a certified cylinder containing $10 \mathrm{ppm}$ of $\mathrm{NO}$ in $\mathrm{N}_{2}$ through a mass flow controller, in order to provide total NO concentrations in the low ppb-range. ${ }^{13} \mathrm{NO}$ and $\mathrm{NO}$ were oxidized to ${ }^{13} \mathrm{NO}_{2}$ and $\mathrm{NO}_{2}$ over solid $\mathrm{CrO}_{3}$ (Levaggi et al., 1972). The $\mathrm{CrO}_{3}$ surface was prepared by immersing firebrick granules into a $17 \%$ aqueous $\mathrm{CrO}_{3}$ solution and drying at $105^{\circ} \mathrm{C}$ in air. The gas flow was humidified to $30-40 \%$ relative humidity by passing it through a vertically mounted $0.5 \mathrm{~cm}$ i.d. porous Teflon tube (Goretex $\left.{ }^{\circledR}\right)$ partially immersed in water, before it entered the reaction chamber containing the $\mathrm{CrO}_{3}$ surface. This procedure led to a complete conversion of $\mathrm{NO}$ to $\mathrm{NO}_{2}$ as routinely checked with a commercial NO/NOx-Analyser (Monitor Labs ML 9841).

$\mathrm{HNO}_{3}$ was produced from the gas phase reaction of $\mathrm{NO}_{2}$ with $\mathrm{OH}$ radicals: the humidified $\mathrm{N}_{2}$ flow containing $\mathrm{NO}_{2}$ was irradiated with $172 \mathrm{~nm}$ light emitted by an excimer lamp in order to produce $\mathrm{OH}$ radicals by the photolysis of gaseous $\mathrm{H}_{2} \mathrm{O}$. The hydroxyl radicals rapidly convert $\mathrm{NO}_{2}$ into $\mathrm{HNO}_{3}$ with a yield of $70 \%$. As noted in our earlier studies, this procedure also leads to some $\mathrm{O}_{3}$ in the ppb range from photolysis of the low amounts of $\mathrm{O}_{2}$ in the system and eventually some $\mathrm{H}_{2} \mathrm{O}_{2}$ (not quantified) from radical recombination reactions (Guimbaud et al., 2002; Vlasenko et al., 2006).

\subsection{Production of the sodium chloride particles}

The deliquesced sodium chloride particles were produced by nebulising a solution containing 1 or $5 \mathrm{~g} \mathrm{~L}^{-1}$ sodium chloride. The resulting droplets were initially dried by passing them through a $1.2 \mathrm{~m}$ long silicagel diffusion drier, followed by an ${ }^{85} \mathrm{Kr}$ source (a bipolar ion source) to establish an equilibrium charge distribution. An electrostatic precipitator removed all charged particles so that only neutral particles were passing on through the experiment to avoid uncontrollable transport losses of charged particles through Teflon tubing. At this point a selector valve allowed to either pass the dry $\mathrm{NaCl}$ particles through a fatty acid evaporator to coat the particles with a thin organic film (see below) or to bypass the coating system to produce pure $\mathrm{NaCl}$ aerosol. Then the aerosol flow was re-humidified above the deliquescence humidity of $\mathrm{NaCl}(>75 \%)$ to deliquesce the aerosol. To complete the deliquescence also in presence of organic coatings, the aerosol was passing through a conditioning chamber with 1 min residence time before entering the aerosol flow tube, where the final humidity was $60 \%$, which is well above the efflorescence point of $\mathrm{NaCl}(\sim 45 \%)$. The humidity in the flow tube was kept below $75 \%$ in order to minimize the effect of $\mathrm{HNO}_{3}$ retention on the walls. The aerosol surface concentration was measured with a Scanning Mobility Particle Sizer (SMPS) consisting of a differential mobility analyser (DMA) and a condensation particle counter (CPC) collecting the aerosols at the exit of the flow tube. It was typically in the range of $1-3 \times 10^{-2} \mathrm{~m}^{2} \mathrm{~m}^{-3}$, and had a variability of $10 \%$ during the experiments ( $1 \sigma$ precision). Since the aerosol liquid water content and the particle diameter are strongly dependent on the relative humidity, the same relative humidity was maintained in both the DMA sheath air and in the aerosol flow tube $(\mathrm{RH}=60 \%)$ by using filtered carrier gas from the flow tube as the sheath gas in the DMA and by thermostating both the aerosol flow tube and the DMA to $23^{\circ} \mathrm{C}$ using cooling jackets connected to the water cycle of a liquid thermostat.

The average diameter of the particles used in most of our experiments was $70 \mathrm{~nm}$ to $90 \mathrm{~nm}$ depending on the $\mathrm{NaCl}$ content of the nebulised $\mathrm{NaCl}$ solution, and the size distribution was lognormal. Although the size of the synthesized $\mathrm{NaCl}$ aerosol was smaller than the average size of sea salt aerosols occurring in the atmosphere (O'Dowd et al., 2001), for aerosol flow tube experiments, the small particle size is more convenient because, (i) uptake of trace gas molecules is less affected by gas-phase diffusion and (ii) particles are less subject to impaction losses in a flow system.

\subsection{Flow reactor for kinetic experiments}

Aerosol and $\mathrm{HNO}_{3}$ flows were mixed in the aerosol flow tube. This flow tube consisted of a PTFE-Teflon tube $(0.8 \mathrm{~cm}$ i.d. $\times 45 \mathrm{~cm}$ ). The flow tube was operated under laminar flow conditions (Reynolds number $=125$ ) at atmospheric pressure (970-980 mbar). $\mathrm{HNO}_{3}$ was admitted through a $4 \mathrm{~mm}$ inner and $6 \mathrm{~mm}$ outer diameter PTFE tube used as a sliding injector. At the tip of this injector the $\mathrm{HNO}_{3}$ flow was dispersed through pinholes in the injector wall. The aerosol was introduced to the flow tube through a T-connector into the annular space between the injector and the flow tube. The flow tube assembly was thermostated to $23^{\circ} \mathrm{C}$ with a water cooled jacked, which corresponded to the room temperature in the laboratory. A new reactor PTFE-tube is installed approximately every three hours to minimise the effect of $\mathrm{HNO}_{3}$ wall losses due to aerosol particle deposition on the walls.

\subsection{Coating of sea salt particles with fatty acid films}

Dry $\mathrm{NaCl}$ aerosol with a flow rate of $300 \mathrm{ml} \mathrm{min}^{-1}$ of $\mathrm{N}_{2}$ was passed through an evaporator consisting of $15 \mathrm{~cm} \times 1 \mathrm{~cm}$ glass tube enclosed in a heated metal-block. A T-junction connected the glass tube with a vertical dead end tube, which held a small sample $(0.5 \mathrm{~g})$ of a fatty acid. The temperature of the fatty acid sample was measured with a thermocouple, which controlled the heating power applied to the metal 

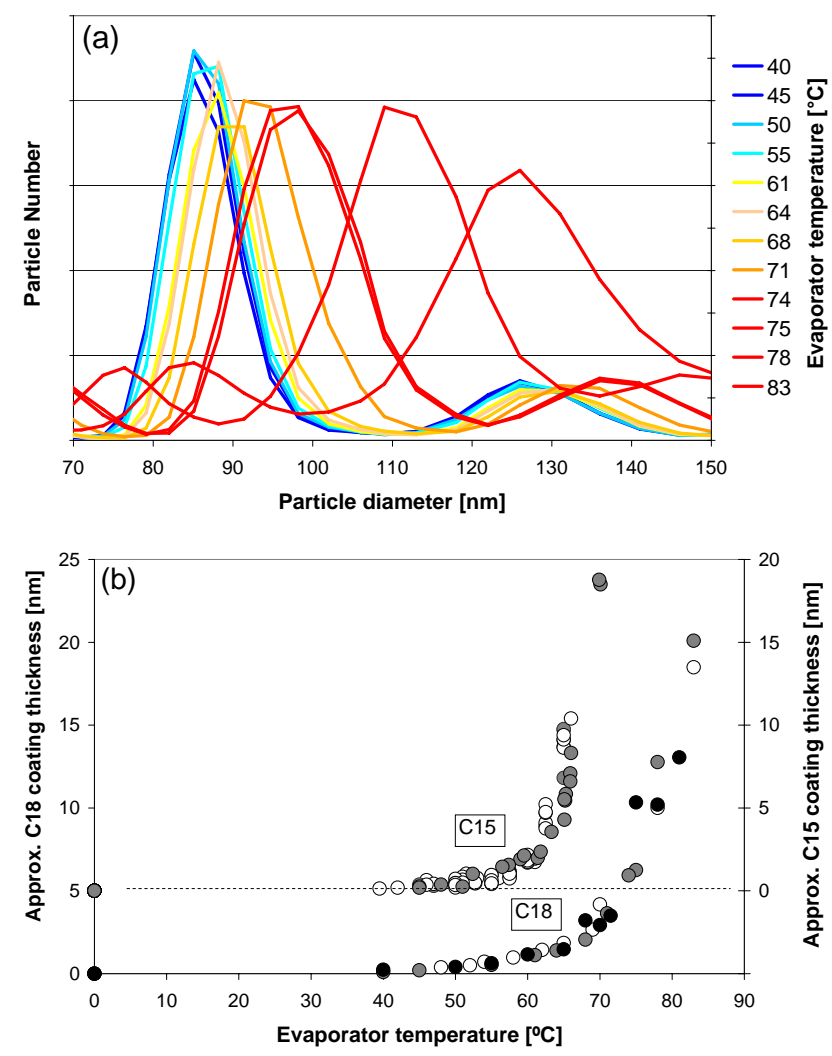

Fig. 1. (a) Particle size distributions of a monodisperse dry aerosol exposed to $\mathrm{C} 18$ acid in the evaporator at different temperatures. The additional modes appearing at larger sizes are from multiply charged particles having the same electrical mobility. We only consider the main mode in this analysis. (b) Growth of dry $\mathrm{NaCl}$ seed particles of different initial diameters $(0: 57 \mathrm{~nm}, \bullet: 85 \mathrm{~nm}$, and $\bullet: 126 \mathrm{~nm}$ ) due to the coating with $\mathrm{C} 18$ acid (right axis) and C15 acid (left axis). The mean increase of the particle radii versus the evaporator temperature is shown. The increase of the particle radius was used to estimate the thickness of the organic coating on the dry aerosol.

block. At the exit of this evaporator the aerosol flow was directed through a thermo-isolated glass tube (gas residence time $5 \mathrm{~s}$ ) to allow for gradual cooling of the gas. To be able to detect the film of fatty acid condensed on the aerosol, a monodisperse aerosol was generated by selecting a specific particle size with an additional DMA (between the nebulizer and the coating apparatus) set to the respective selector voltage. With the SMPS system, then the sizes of coated and uncoated particles were measured, respectively, to estimate the load of the organics on the aerosol. In Fig. 1a the size distribution of a coated $\mathrm{NaCl}$ seed aerosol is shown as a function of the temperature of $\mathrm{C} 18$ acid in the evaporator. Figure $1 \mathrm{~b}$ shows the increase of the film thickness on seed aerosol coated with $\mathrm{C} 18$ acid and $\mathrm{C} 15$ acid as a function of the evaporator temperature. We do not know, whether the organics form a homogeneous coating on the dry particles or condense as a separate droplet attached to the $\mathrm{NaCl}$ particle. Therefore, the estimates of organic volume based on the changes in the equivalent mobility diameter without any shape corrections will carry a significant uncertainty.

$\mathrm{NaCl}$ aerosol containing humic acids, as a model for water soluble organic compounds, were produced by nebulising solutions composed of a mixture of $\mathrm{NaCl}$ with a variable amount of humic acids (humic acid sodium salt, Aldrich). The $\mathrm{pH}$ of the nebulised solutions was adjusted to $\mathrm{pH}=6.5$ by addition of $\mathrm{HCl}$.

\subsection{The detection system and its calibration}

After passing through the flow tube, the gas entered a narrow parallel-plate diffusion denuder with three compartments, each lined with parallel plates coated to selectively absorb $\mathrm{HNO}_{3}(\mathrm{~g}), \mathrm{HONO}(\mathrm{g})$ and $\mathrm{NO}_{2}(\mathrm{~g})$, respectively, followed by a particle filter collecting the particles. To each denuder compartment and to the filter a CsI scintillation counter (Caroll\&Ramsey Associates, Model 105) was attached. For $\mathrm{HNO}_{3}$, the walls of the first pair of denuder plates (10 cm long) were wetted with a saturated solution of $\mathrm{NaCl}$ in methanol and then dried in $\mathrm{N}_{2}$. For HONO, the second pair of denuder plates $(10 \mathrm{~cm}$ long) was wetted with a $1.4 \%$ solution of $\mathrm{Na}_{2} \mathrm{CO}_{3}$ in $50 \%$ methanol/water and subsequently dried in $\mathrm{N}_{2}$. A small amount of $\mathrm{HONO}$ (several \% relative to $\mathrm{HNO}_{3}$ ) was always produced from the reaction of $\mathrm{OH}$ with traces of $\mathrm{NO}$ during $\mathrm{HNO}_{3}$ production. We note that also $\mathrm{HCl}$ released from the particles is absorbed on this section of the denuder. For $\mathrm{NO}_{2}$, the third pair of denuder plates (20 $\mathrm{cm}$ long) was coated with a solution of $1 \% \mathrm{~N}$-(1-naphthyl) ethylenediamine dihydrochloride (NDA), $1 \% \mathrm{KOH}$ and $10 \%$ water in methanol. In this denuder system, the gas passes in a laminar flow profile. The absorption of molecules capable of being taken up on the denuder plates is controlled by lateral diffusion, whereas the particles pass through the parallel plate denuder with close to $100 \%$ efficiency due to their very low diffusion coefficient. Under the flow conditions applied, the characteristic time for the separation of $\mathrm{HNO}_{3}$ from the aerosol was about $20 \mathrm{~ms}$. The performance of this system had been demonstrated previously (Ammann, 2001). The $\mathrm{HNO}_{3}$ uptake coefficient was derived from the concentration change of $\mathrm{HNO}_{3}$ in the gas phase at the end of the flow tube when the aerosol was admitted to the flow tube, and from the concentration equivalent of $\mathrm{HNO}_{3}$ taken up by the particles. At a given flow rate, these concentrations were obtained from the flux of ${ }^{13} \mathrm{~N}$-labelled molecules into the corresponding trap, $j$, multiplied by the ratio of labelled to non-labelled molecules. The concentration of non-labelled molecules was measured with a chemiluminescence detector. The flux into trap $j, I_{j}$, can be derived from the difference between two consecutive activity measurements, $A_{j, i-1}$ and $A_{j, i}$, recorded at times $t_{i-1}$ and $t_{i}$, as shown in Eq. (1), where $\lambda$ is the decay constant of ${ }^{13} \mathrm{~N}\left(\lambda=0.00116 \mathrm{~s}^{-1}\right)$. Each activity, $A_{j}$, was recorded 


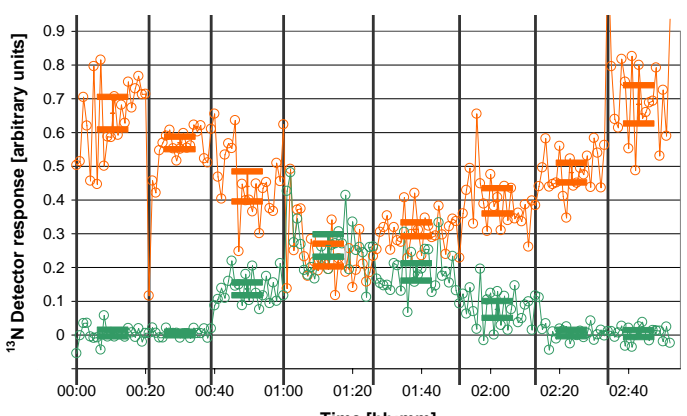

Time [hh:mm]

\begin{tabular}{|l|c|c|c|c|c|c|c|c|}
\hline Injector position $[\mathrm{cm}]$ & 0 & 45 & 45 & 45 & 35 & 35 & 35 & 0 \\
\hline Aerosol in reactor & & & $\times$ & $\times$ & $\times$ & $\times$ & & \\
\hline Stearic acid coating & & & $\times$ & & & $\times$ & & \\
\hline
\end{tabular}

Fig. 2. Detector signal of the $\mathrm{HNO}_{3}$ (g)-denuder (orange circles) and the particle filter (green circles) for a typical experiment. The detector signals were modified according to Eq. (1) to show the flux of ${ }^{13} \mathrm{~N}$ into the denuder or filter, respectively. The black vertical lines symbolize the change of the experimental conditions according to the entries in the table at the bottom of the figure. The error bars represent the borders of the $95 \%$ confidential interval for the mean value of the detector signals.

with an integration time of $1 \mathrm{~min}$.

$I_{j}=\frac{A_{j, i}-A_{j, i-1} e^{-\lambda\left(t_{i}-t_{i-1}\right)}}{1-e^{-\lambda\left(t_{i}-t_{i-1}\right)}}$

The relative counting efficiency of each $\gamma$ detector is obtained by accumulating a certain amount of ${ }^{13} \mathrm{NO}_{2}$ on a pair of denuder plates and then moving those plates in front of each other detector.

\section{Results}

In a first series of experiments the uptake of gaseous $\mathrm{HNO}_{3}$ on pure (uncoated) deliquesced $\mathrm{NaCl}$ particles was compared with that on particles coated with a thin film of $\mathrm{C} 18$ acid. These experiments usually involved the measurements of the uptake of $\mathrm{HNO}_{3}$ at four different contact times in the range of $0-1.9 \mathrm{~s}(0-45 \mathrm{~cm}$ reactor length). For each contact time a direct comparison of the $\mathrm{HNO}_{3}$ uptake on coated and uncoated aerosols was performed by either directing the $\mathrm{NaCl}$ aerosol through the $\mathrm{C} 18$ acid vapour oven or by-passing it. Figure 2 illustrates this procedure for an experiment and shows the response of the $\gamma$-detectors (evaluated according to Eq. (1) for gaseous and particle-bound ${ }^{13} \mathrm{~N}$ ). A typical experiment involved the following steps. First, the injector was pulled all the way into the reactor, to measure the initial $\mathrm{H}^{13} \mathrm{NO}_{3}(\mathrm{t}=0)$ concentration after mixing downstream of the injector tip. No aerosol was introduced into the reactor at this and at the following stage. Next, the injector was pulled out to a certain reaction length leading to a drop in the $\mathrm{H}^{13} \mathrm{NO}_{3}(\mathrm{~g})$ signal,

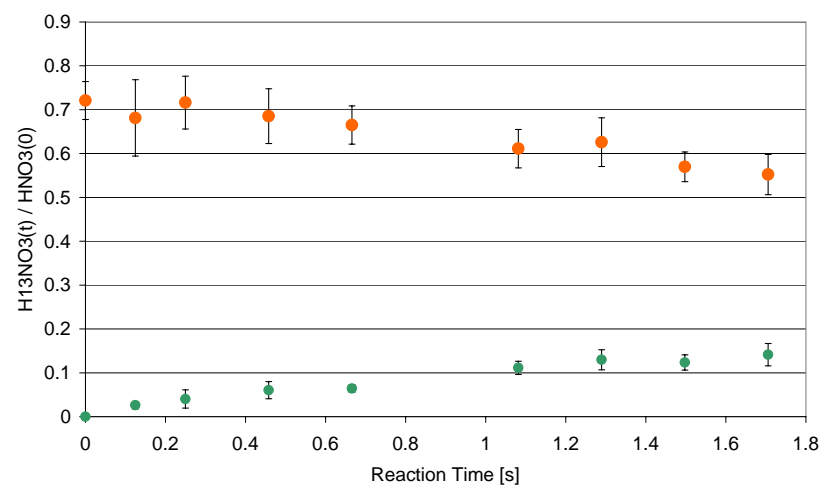

Fig. 3. Experimental result for the phase transfer of gaseous $\mathrm{HNO}_{3}$ to deliquesced $\mathrm{NaCl}$ aerosol coated with $\mathrm{C} 18$ acid at $70^{\circ} \mathrm{C}$ as a function of the reaction time. The orange and green circles depict the ratio of the $\mathrm{HNO}_{3}(\mathrm{~g})-{ }^{13} \mathrm{~N}$ and particulate ${ }^{13} \mathrm{~N}$ signals at a given reaction time to the $\mathrm{HNO}_{3}(\mathrm{~g})-{ }^{13} \mathrm{~N}$ signal at injector position 0 .

corresponding to the longer retention time of $\mathrm{H}^{13} \mathrm{NO}_{3}$ at the reactor walls and its concurrent radioactive decay. This indicates that the net residence time of $\mathrm{HNO}_{3}$ molecules is much longer (several minutes) than that of the carrier gas or the particles ( $2 \mathrm{~s}$ at maximum), even for a clean PFA tube, which is the typical behaviour of $\mathrm{HNO}_{3}$ in a flow tube, see also Guimbaud et al. (2002) and Vlasenko et al. (2006) for a discussion of this issue. Finally, the $\mathrm{NaCl}$ aerosol was introduced leading to another drop in the $\mathrm{HNO}_{3}(\mathrm{~g})$ signal and the appearance of the ${ }^{13} \mathrm{~N}$ signal on the particle filter, indicating that a part of the labelled $\mathrm{H}^{13} \mathrm{NO}_{3}$ molecules had been taken up by the aerosol. In the experiment shown, first a $\mathrm{C} 18$ acid coated $\mathrm{NaCl}$ aerosol was introduced, and after $30 \mathrm{~min}$, the vapour oven was bypassed to have an uncoated $\mathrm{NaCl}$ aerosol in the reactor. As can be seen from the rising signal at the particle filter and the concurrently decreasing signal for $\mathrm{H}^{13} \mathrm{NO}_{3}(\mathrm{~g})$, the pure deliquesced $\mathrm{NaCl}$ aerosol has a higher reactivity than the coated aerosol. The injector position was changed to study the reaction at a different contact time and the same procedure was performed but in reverse order. The determination of the wall loss rate of $\mathrm{H}^{13} \mathrm{NO}_{3}$ at the end of an experiment often yielded a somewhat higher loss of the ${ }^{13} \mathrm{~N}$ tracer. Usually, the PFA-reactor tube was replaced after such a reaction sequence to avoid a further increase of the wall losses of $\mathrm{H}^{13} \mathrm{NO}_{3}$. Any impurity, even when not directly consuming $\mathrm{HNO}_{3}$ (such as deposited, fully processed aerosol particles), could enhance the retention of $\mathrm{HNO}_{3}$ on the reactor walls and consequently increase the apparent wall loss. Figure 3 shows the relative change of the detector signals with varying $\mathrm{HNO}_{3}$-aerosol contact times for an experiment. With increasing reaction time an increasing fraction of the ${ }^{13} \mathrm{~N}$ signal was received from the aerosol phase. The tracer specific detector signal was attributed to a $\mathrm{HNO}_{3}$ concentration by scaling the initial signal at $t=0$ to the initial $\mathrm{HNO}_{3}$ concentration $(30 \mathrm{ppb})$, which was derived from the concentration 
Table 1. Reproducibility of the measured uptake coefficients $\gamma$ for the reaction of $\mathrm{HNO}_{3}(\mathrm{~g})$ with C18 coated and uncoated deliquesced $\mathrm{NaCl}$-aerosol. The coating was roughly $50 \%$ of a monolayer on the deliquesced particles.

\begin{tabular}{lllll}
\hline Exp. \# & $\begin{array}{l}\gamma \text { on pure } \mathrm{NaCl} \text { (aerosol } \\
\text { phase accumulation } \\
\left.\text { of }{ }^{13} \mathrm{~N}\right)^{\mathrm{a}, \mathrm{c}}\end{array}$ & $\begin{array}{l}\gamma \text { on pure } \mathrm{NaCl} \\
\left(\text { loss of } \mathrm{HNO}_{3}(\mathrm{~g})-{ }^{13} \mathrm{~N}\right)^{\mathrm{b}, \mathrm{c}}\end{array}$ & $\begin{array}{l}\gamma \text { on stearic acid coated } \\
\mathrm{NaCl}(\text { aerosol phase accu- } \\
\left.\text { mulation of }{ }^{13} \mathrm{~N}\right)^{\mathrm{a}, \mathrm{c}}\end{array}$ & $\begin{array}{l}\gamma \text { on stearic acid coated } \\
\mathrm{NaCl}(\mathrm{loss} \text { of } \mathrm{HNO}(\mathrm{g})-\end{array}$ \\
\hline 1 & $0.50 \pm 0.14$ & $0.70 \pm 0.28$ & $0.23 \pm 0.10$ & $0.30 \pm 0.06$ \\
2 & - & - & $0.20 \pm 0.02$ & $0.14 \pm 0.15$ \\
3 & $0.44 \pm 0.15$ & $0.37 \pm 0.06$ & $0.20 \pm 0.07$ & $0.17 \pm 0.03$ \\
4 & $0.48 \pm 0.19$ & $0.79 \pm 0.05$ & $0.35 \pm 0.08$ & $0.23 \pm 0.19$ \\
5 & $0.55 \pm 0.24$ & $0.30 \pm 0.16$ & $0.35 \pm 0.12$ & $0.17 \pm 0.11$ \\
6 & $0.68 \pm 0.20$ & $0.62 \pm 0.15$ & $0.18 \pm 0.08$ & $0.40 \pm 0.21$ \\
7 & $0.46 \pm 0.20$ & $0.47 \pm 0.23$ & $0.18 \pm 0.07$ & $0.22 \pm 0.14$ \\
8 & $0.30 \pm 0.07$ & $0.49 \pm 0.11$ & $0.14 \pm 0.07$ & $0.26 \pm 0.08$ \\
mean ${ }^{\mathrm{d}}$ & $0.49 \pm 0.11$ & $0.53 \pm 0.18$ & $0.23 \pm 0.08$ & $0.25 \pm 0.09$ \\
\hline
\end{tabular}

a see Eqs. (4) and (5).

b see Eqs. (3) and (5).

${ }^{c}$ the reported error for the individual experiments represents the standard deviation $(1 \sigma)$ of the $4 \gamma$ determinations within each experiment and includes no systematic errors.

$\mathrm{d}$ the reported mean for $\gamma$ is a non weighted average and the reported error represents the standard error $(1 \sigma)$ of the mean of the results of the individual experiments and includes no systematic errors (which are around $\pm 30 \%$ ).

of $\mathrm{NO}_{2}$ introduced into the reactor and the $\mathrm{NO}_{2}$ to $\mathrm{HNO}_{3}$ conversion efficiency. The latter was determined from the change in the ${ }^{13} \mathrm{NO}_{2}$ signal observed when switching on and off the UV lamp.

\subsection{Calculation of the uptake coefficient}

The uptake coefficient $\gamma$ is defined as the ratio between the net flux of molecules from the gas phase to the particle phase and the gas-kinetic collision rate of the molecules with the surface of the particles. The observations from the individual experiments as shown in Figs. 2 and 3 allow the determination of the rate of change of gas-phase and particulate phase concentrations and calculating the uptake coefficient as reported earlier (Guimbaud et al., 2002). The equation for the depletion of radioactively labelled $\mathrm{H}^{13} \mathrm{NO}_{3}(\mathrm{~g})$ in the flow tube is given by

$$
\frac{\left[\mathrm{HNO}_{3}(\mathrm{~g})\right](t)}{\left[\mathrm{HNO}_{3}(\mathrm{~g})\right](t=0)}=e^{-\left(k_{\mathrm{w}}+k_{\mathrm{p}}\right) t}
$$

where $k_{\mathrm{W}}$ is the first order wall loss rate of $\mathrm{H}^{13} \mathrm{NO}_{3}(\mathrm{~g})$ and $k_{\mathrm{p}}$ the first order loss to the particle phase. This approach assumes a constant uptake to the aerosol during the residence time of the aerosol in the flow reactor.

$k_{\mathrm{W}}$ is determined from the decay of $\mathrm{H}^{13} \mathrm{NO}_{3}(\mathrm{~g})$ in absence of aerosol $\left(k_{\mathrm{p}}=0\right)$. The loss rate of $\mathrm{H}^{13} \mathrm{NO}_{3}(\mathrm{~g})$ in presence of the aerosol then allows determining the sum of $k_{\mathrm{p}}$ and $k_{\mathrm{w}}$. The kinetics of appearance of $\mathrm{H}^{13} \mathrm{NO}_{3}$ in the particulate phase is given by:

$\frac{\left[\mathrm{HNO}_{3}(\mathrm{p})\right](t)}{\left[\mathrm{HNO}_{3}(\mathrm{~g})\right](t=0)}=\frac{1-\mathrm{e}^{-\left(k_{\mathrm{w}}+k_{\mathrm{p}}\right) t}}{1+\frac{k_{\mathrm{W}}}{k_{\mathrm{p}}}}$

where $\left[\mathrm{HNO}_{3}(\mathrm{p})\right](t)$ is the concentration of $\mathrm{H}^{13} \mathrm{NO}_{3}$ in the particulate phase.

The first order loss rate coefficient $k_{\mathrm{p}}$ for the reaction of $\mathrm{HNO}_{3}$ with the aerosol is related to the net uptake coefficient via Eq. (4), where $S$ is the aerosol surface concentration measured during the experiment and $\omega$ is the mean thermal velocity of $\mathrm{HNO}_{3}$, given as $\omega=(8 R T /(\pi M))^{1 / 2}$ with $R, T$, and $M$ being the gas constant, the absolute temperature, and the molar weight of $\mathrm{HNO}_{3}$, respectively.

$k_{\mathrm{p}}=\frac{\gamma S \omega}{4}$

Here no correction of $\gamma$ for limitation by the gas phase diffusion of $\mathrm{HNO}_{3}$ was applied. As discussed earlier (Guimbaud et al., 2002) based on an estimated mean free path of $130 \mathrm{~nm}$ for $\mathrm{HNO}_{3}$ in the reactor and $\gamma=0.5$, such corrections would change the rate of uptake by about $8 \%$ for the reaction of $\mathrm{HNO}_{3}$ with a monodisperse $100 \mathrm{~nm}$ aerosol. Integrated over a typical polydisperse aerosol size spectrum with $100 \mathrm{~nm}$ mean diameter the diffusion limitation affects $\gamma$ by at maximum $20 \%$.

\subsection{Uptake of $\mathrm{HNO}_{3}$ to neat $\mathrm{NaCl}$ particles}

Table 1, column 2 and 3 show the uptake coefficient of gaseous $\mathrm{HNO}_{3}$ on neat deliquesced $\mathrm{NaCl}$ aerosol derived 
from seven individual experiments. The aim of these experiments was to repeat an experiment under almost identical conditions to capture the day-to-day reproducibility and also to compare with our earlier results (Guimbaud et al., 2002) in view of other more recent studies on this reaction with differing kinetic results (Tolocka et al., 2004; Saul et al., 2006; Liu et al., 2007). The initial $\mathrm{HNO}_{3}$ concentration of the experiments was 30-32 ppb, except in experiment \#5 where the initial concentration was $10 \mathrm{ppb}$. The deliquesced $\mathrm{NaCl}$ aerosol had a log-normal size distribution and the mean diameter was $70 \mathrm{~nm}$ in experiments $1-4$, and $90 \mathrm{~nm}$ in experiments $5-8$. Each experiment involved the measurement of the uptake coefficient at four reaction times between 0.35 and $1.9 \mathrm{~s}$. In column 2 the uptake coefficient derived from the accumulation of ${ }^{13} \mathrm{~N}$ in the particle phase is shown (see Eq. 4), whereas the uptake derived from the loss of gaseous $\mathrm{HNO}_{3}(\mathrm{~g})$ is shown in column 3 (see Eq. 3). As can be seen in Table 1 the measured uptake coefficient varied significantly between the experiments (20-40\% standard deviation). This relatively low degree of reproducibility results from several difficulties in such an experiment. First a stable production rate of the ${ }^{13} \mathrm{~N}$ isotope has to be maintained, which was reached only during about $50 \%$ of the allocated proton beam periods. Further, the online aerosol and $\mathrm{HNO}_{3}$ synthesis have to be constant, which involves the control of several flows and relative humidities within the system, and the coatings of the parallelplate diffusion denuder had to be renewed daily to guarantee a reproducible performance. And last, as the wall loss of $\mathrm{HNO}_{3}$ in the reactor increased during extended exposure to aerosol flow, the reactor had to be replaced several times during a series of experiments to keep the reaction conditions reproducible. All absolute determinations of $\gamma$ reported here are additionally affected by a systematic error of the aerosol surface measurements by SMPS in the order of $\pm 30 \%$.

Our experimental result for the uptake of $\mathrm{HNO}_{3}$ on uncoated deliquesced $\mathrm{NaCl}$ aerosols of $\gamma=0.5 \pm 0.2$ is identical with the value previously obtained by the same method (Guimbaud et al., 2002). As discussed previously, it compares well with the data measured by Abbatt and Waschewsky (Abbatt and Waschewsky, 1998), who derive a lower limit for $\gamma$ of 0.2 for the uptake to deliquesced micrometer sized $\mathrm{NaCl}$ particles at $75 \%$ relative humidity. Similarly it seems to be consistent with the most recent study by Liu et al. (2007), who found effective uptake coefficients up to about 0.2 under partial diffusion control. However, a more significant discrepancy exists between $\gamma$ reported here and that reported by Tolocka et al. (2004) for the same reaction. They derived $\gamma=4.9( \pm 0.27) \times 10^{-3}$ from the determination of the depletion of $\mathrm{Cl}^{-}(\mathrm{aq})$ in $100 \mathrm{~nm}$ deliquesced $\mathrm{NaCl}$ aerosols at $80 \%$ relative humidity by single particle mass spectrometry under rather similar conditions as in this study. In a recent study (Saul et al., 2006) the same group reinvestigated the reaction with an improved experimental set-up and report $\gamma$ as 0.11 at $60 \%$ and as 0.06 at $75 \%$ relative humidity based on the chloride depletion in $100 \mathrm{~nm}$ aerosol, which seems to come into better agreement with the other previous studies. To further investigate the discrepancy between $\gamma$ derived from the transfer of $\mathrm{HNO}_{3}$ into the particulate phase (this study) and derived from the chlorine depletion in single particles, an ion chromatographic analysis of $\mathrm{Cl}^{-}$and $\mathrm{NO}_{3}^{-}$was performed of the aerosol (mean surface concentration $2.8 \times 10^{-2} \mathrm{~m}^{2} \mathrm{~m}^{-3}$ ) collected on the particle filter during 1 hour in one typical experiment. The results indicated an exchange of $\mathrm{Cl}^{-}$against $\mathrm{NO}_{3}^{-}$of $1.9 \%, 3.5 \%$, $3.8 \%, 4.6 \%$, and $6.4 \%$ after $0.2,0.4,0.85,1.25$, and $1.7 \mathrm{~s}$ reaction time in presence of $25 \mathrm{ppb} \mathrm{HNO}_{3}(\mathrm{~g})$. This $\mathrm{HNO}_{3}$ uptake is based only on a single experiment with 5 data points, but would support a high uptake coefficient of $0.4 \pm 0.3$ which corresponds to the value determined by the radioactive tracer technique and is in contrast to the aerosol mass spectrometric analysis by Tolocka et al. (2004). Based on the arguments already stated by Guimbaud et al. (2002), the uptake on pure deliquesced $\mathrm{NaCl}$ particles in this size range seems to be limited by bulk accommodation into the aqueous solution. We have not performed a detailed analysis of the flow patterns in our flow reactor. Given the short interaction times, we have to rely on fast mixing of the gas and aerosol flows, which we might overestimate. In case mixing is slower than we anticipate, this would lead to an even higher uptake coefficient, as the effective interaction time would be below that used in the analysis. Therefore, remaining uncertainty regarding mixing would allow us to rather constrain the bulk accommodation coefficient to values between 0.5 and 1.0.

\subsection{Uptake of $\mathrm{HNO}_{3}$ to coated $\mathrm{NaCl}$ particles}

Columns 4 and 5 in Table 1 represent measured uptake coefficients of $\mathrm{HNO}_{3}$ on deliquesced aerosol particles coated with a thin film of $\mathrm{C} 18$ acid. The values given in column 4 are derived from the accumulation of ${ }^{13} \mathrm{~N}$ in the particle phase, the values in column 5 from the loss of $\mathrm{HNO}_{3}(\mathrm{~g})$. In all cases the coating was produced by passing the aerosol through the evaporator containing the $\mathrm{C} 18$ acid and held at $70^{\circ} \mathrm{C}$. This results in an approximately $3 \mathrm{~nm}$ thin layer of $\mathrm{C} 18$ acid on the dry $\mathrm{NaCl}$ aerosol (Fig. 1). The length of the $\mathrm{C} 18$ backbone of stearic acid is approximately $1.5 \mathrm{~nm}$, hence the amount could cover the dry aerosol by more than one monolayer. In the experiments deliquesced aerosol at a relative humidity of $60 \%$ was used. At this humidity the aerosol diameter is about a factor of 1.6 larger than under dry conditions and its surface by approximately a factor of 2.6. The amount of stearic acid on the deliquesced aerosol surface is then estimated to correspond to about $75 \%$ of a monolayer. As the quantification is based on various assumptions, this value should be taken as an approximation with an uncertainty of about a factor of 3 . The results presented in Table 1 and all direct comparisons of coated and neat aerosol as shown in Fig. 2 indicate that the reactivity of the coated aerosol is significantly lower than that of a pure deliquesced $\mathrm{NaCl}$ aerosol by a factor of about 2. The direct comparison of the reactivity of $\mathrm{C} 18$ acid coated 


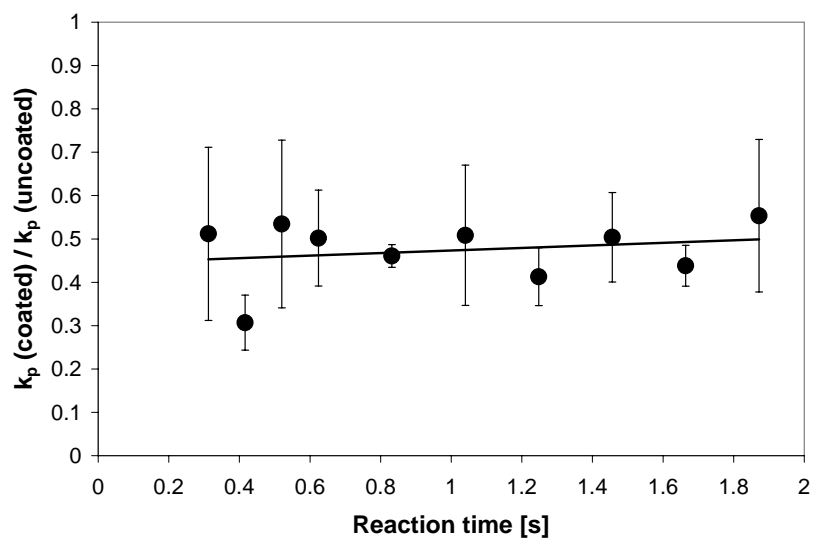

Fig. 4. Ratio of the reactivity of $\mathrm{NaCl}$ aerosol coated at $70^{\circ} \mathrm{C}$ with stearic acid to that of pure deliquesced $\mathrm{NaCl}$ aerosol with gaseous $\mathrm{HNO}_{3}(\mathrm{~g})$ as a function of the contact time. The results are mean values of the ratio of $k_{\mathrm{p}}$ of coated aerosol to $k_{\mathrm{p}}$ of uncoated aerosol evaluated at individual injector positions for all experiments also listed in Table 1.

and pure $\mathrm{NaCl}$ aerosol, i.e. when the only change in the experiment was that the aerosol was either passing through the evaporator or not, is shown in Fig. 4, where the ratio of $k_{\mathrm{p}}$ for coated to that for uncoated particles was calculated for each injector position, averaging the results obtained from $\mathrm{HNO}_{3}(\mathrm{~g})-{ }_{-}^{13} \mathrm{~N}$ and particulate ${ }^{13} \mathrm{~N}$ through Eqs. (2) and (3). It can be seen that this ratio was constant $(0.5 \pm 0.2)$ within the experimental precision over a range of contact times from 0.3 to $1.9 \mathrm{~s}$. This indicates that the presence of the coating did not induce a time dependence. Such a time dependence might have been expected in view of a possibly complex process of uptake of $\mathrm{HNO}_{3}$, including adsorption on the surfactant films and transfer accross it to the aqueous phase. The lack of time dependence is important for the first order analysis of the data for the coated particles.

In a next set of experiments it was investigated how the reactivity of coated $\mathrm{NaCl}$ aerosol depends on the amount $\mathrm{C} 18$ acid on the aerosol surface and how other types of nonbranched fatty acids affect the uptake of gaseous $\mathrm{HNO}_{3}$. The experiments have been performed with an initial concentration of $30 \mathrm{ppb} \mathrm{HNO}_{3}$ and at $60 \%$ relative humidity and with a fixed contact time of $1.7 \mathrm{~s}$. The temperature of the fatty acid in the vapour chamber was varied to condense different amounts of the fatty acids on the seed aerosol. The experiment was performed with a series of saturated linear fatty acids $(\mathrm{C} 18, \mathrm{C} 15, \mathrm{C} 12$, and $\mathrm{C} 9)$ to detect trends in the behaviour of the coatings and with a monounsaturated $\mathrm{C} 18$ fatty acid, oleic acid (cis-9-octadecenoic acid), which has a non-linear conformation, for comparison. The amount of fatty acid in the aerosols was approximated as described in Sect. 2.3 and Fig. 1. Again the reactivities of the aerosol coated under the various conditions were directly compared with that of uncoated seed $\mathrm{NaCl}$ aerosol measured in adja-
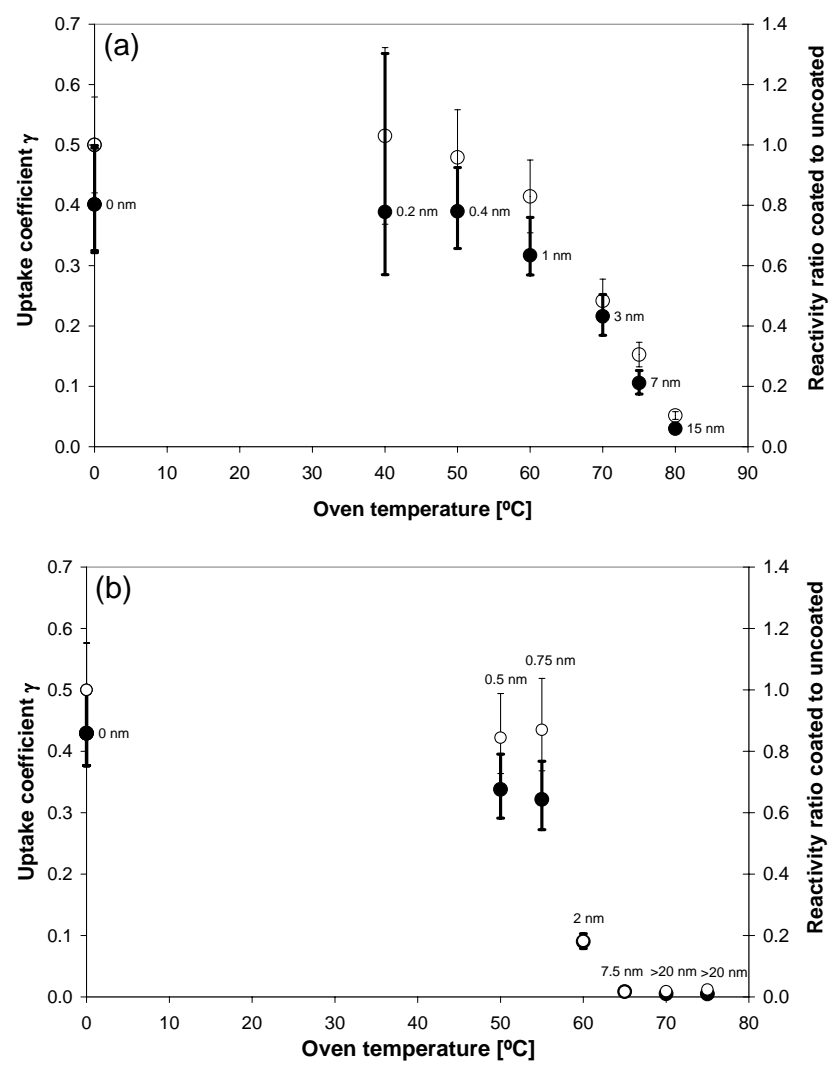

Fig. 5. Uptake coefficient $\gamma$ for the reaction of $\mathrm{HNO}_{3}(\mathrm{~g})$ with deliquesced $\mathrm{NaCl}$ aerosol coated with varying amounts of stearic acid (C18) (a) and pentadecanoic acid (C15) (b). In each panel the uptake coefficient $\gamma$ is depicted as filled circles ( $\bullet$, left axis) and the ratio of the reactivity of coated vs. that of pure $\mathrm{NaCl}$ aerosol is shown as empty circles (o, right axis). The values next to the symbols give our estimate of the coating thickness on the dry aerosol.

cent experiments, as shown in Fig. 2. In Fig. 5a the reactivity of $\mathrm{C} 18$ acid coated aerosol is shown for different coating thicknesses. It is evident that the reactivity decreased with increasing amounts of $\mathrm{C} 18$ acid reaching a value of $\gamma=0.1$ at a $\mathrm{C} 18$ acid content, which approximately corresponds to the amount of a monolayer on the deliquesced aerosol, and $\gamma<0.1$ for larger stearic acid loadings. This effect manifests in both the $\gamma$ coefficients derived from the individual measurements with coated aerosol, as well as in the ratios of reactivity of the coated to the uncoated aerosol from two adjacent experiments. For the $\mathrm{C} 15$ saturated fatty acid (see Fig. 5b), a similar reduction of the uptake coefficient to $\gamma=0.14$ was measured at a fatty acid amount, which is estimated to still be less than a monolayer on the deliquesced aerosol. For C15 fatty acid loadings corresponding to one monolayer or an excess of that, uptake coefficients in the order of $\gamma=0.01$ are obtained. As shown in Fig. 6a, no significant inhibitory effect on the $\mathrm{HNO}_{3}(\mathrm{~g})$ uptake was observed, when either the shorter chain $\mathrm{C} 12$ and $\mathrm{C} 9$ acids or the non-linear oleic acid 
were condensed on the aerosol in amounts ranging from submonolayer quantities to amounts in excess of a monolayer on the deliquesced aerosol.

The observed variability is within the reproducibility of the experiment described above. We also note that as mentioned earlier, the larger the apparent coating thickness is, the more likely is it that a change in shape was accompanying the coating process, which is not accounted for.

A large fraction of the organic content of aerosol are high molecular mass, oxygenated species (Zappoli et al., 1999; Gelencser et al., 2000; Krivacsy et al., 2000; Cappiello et al., 2003; Mayol-Bracero et al., 2002; Cavalli et al., 2004; Graham et al., 2002; Facchini et al., 2000; Mukai and Ambe, 1986) with humic-like complex structures. Such materials also show surface-active properties and can be considered as anionic surfactants (Ma et al., 2007; Cavalli et al., 2004; de Moraes and Rezende, 2004; Facchini et al., 2000). As a model compound for such water soluble oxidised organic matter we have chosen a humic acid (Aldrich Humic Acid) and investigated if large amounts of this humic acid in $\mathrm{NaCl}$ aerosol have an effect on the uptake of $\mathrm{HNO}_{3}(\mathrm{~g})$. The humic acid containing aerosol was produced by nebulizing $\mathrm{NaCl}$ solutions containing variable fractions of the humic acid as described in Sect. 2.4. Figure 6b shows the measured uptake coefficients on deliquesced $\mathrm{NaCl}$ aerosol containing dry mass fractions of $0-40 \%$ of humic acid. No significant change in the uptake coefficient of $\mathrm{HNO}_{3}(\mathrm{~g})$ was observed due to the presence of the humic acid.

\section{Discussion of effects of fatty acid coatings}

The observation that the saturated $\mathrm{C} 18$ and $\mathrm{C} 15$ acids lead to a significant depletion of the reaction rate of $\mathrm{HNO}_{3}(\mathrm{~g})$ with aqueous $\mathrm{NaCl}$ particles, but that no effect was observed for the saturated $\mathrm{C} 12$ and $\mathrm{C} 9$ acids nor for the monounsaturated oleic acid (C18:1), can not be explained simply by the amounts of the organic compounds deposited on the particles. Therefore, it can be concluded, that it is the capability of the specific compounds to form an organic monolayer with a specific structure, which leads to the reactivity reduction. Table 2 shows some physical properties of the fatty acids investigated here that determine their ability to form monolayers on aqueous surfaces. The properties of the fatty acids depend on the length of their carbon chain. It determines their solubility in water, their gas-particle partitioning, the state of the film, which they form on the water surface and the thickness of a monolayer they form. The water solubility of the investigated saturated fatty acids decreases with increasing alkyl chain length. For the $\mathrm{C} 9$ acid exhibiting the highest water solubility of the fatty acids investigated less than $1 \%$ of a monolayer amount is soluble in a pure aqueous particle of the size as used in our experiments. The high ionic strength of $\mathrm{NaCl}$ aerosol (at $60 \%$ relative humidity they contain about $10 \mathrm{~mol} \mathrm{NaCl} \mathrm{kg}^{-1}$ ) is expected to further reduce the solubil-

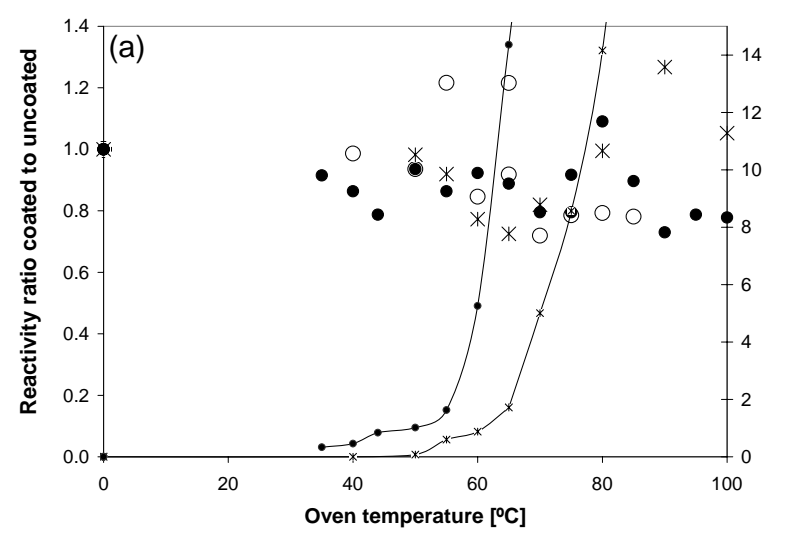

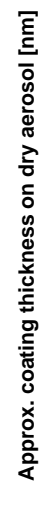

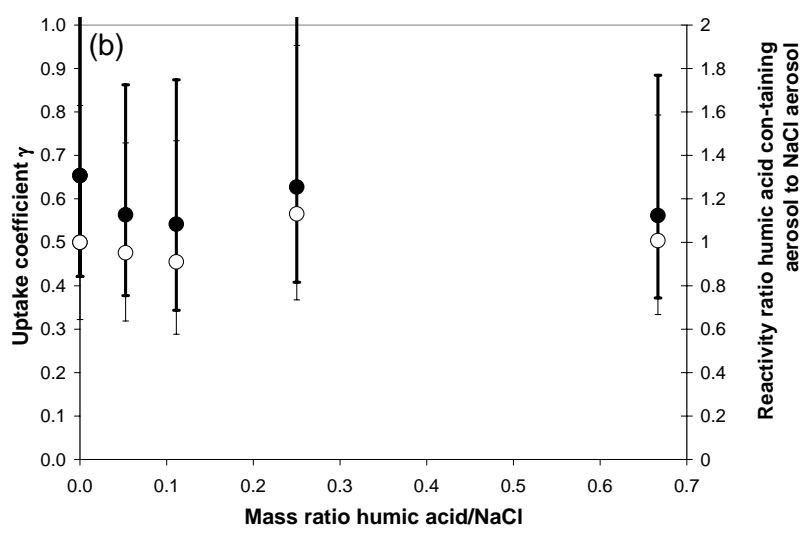

Fig. 6. Uptake of $\mathrm{HNO}_{3}(\mathrm{~g})$ to deliquesced $\mathrm{NaCl}$ aerosol coated with different amounts of lauric acid (C12), pelargonic acid (C9), oleic acid (C18:1) and to $\mathrm{NaCl}$ aerosol containing humic acids. (a) ratio of the reactivity of aerosol coated with $\mathrm{C} 12$ (•), C9 (०), and $\mathrm{C} 18: 1(*)$ to that of uncoated $\mathrm{NaCl}$ aerosol. The lines represent our estimate of the coating thickness on the dry aerosol with increasing fatty acid temperatures in the coating oven for $\mathrm{C} 12(-\bullet)$ and $\mathrm{C} 18: 1$ (*).(b) uptake coefficient $\gamma$ for $\mathrm{HNO}_{3}$ (g) to humic acid containing aerosol as a function of the mass ratio of humic acids to $\mathrm{NaCl}$. The uptake coefficient $\gamma$ is depicted as filled circles ( $\bullet$, left axis) and the ratio of the reactivity of humic acid containing $\mathrm{NaCl}$ to that of pure $\mathrm{NaCl}$ aerosol is shown as empty circles (o, right axis).

ity of the fatty acids, and hence we conclude that none of the C9-C18 would be too soluble to prevent the formation of a stable surface film under the given experimental conditions. On the other hand, the conjugate base ions could form micelles within the particles (Tabazadeh, 2005), leading to increased effective solubility. However, in absence of basic cations in our pure $\mathrm{NaCl}$ particles, with $p K_{\mathrm{a}}$ values between 7 and 10, the fatty acids remain protonated in a monolayer on an aqueous subphase (Kanicky et al., 2000; Kanicky and Shah, 2002). Also the vapour pressure of fatty acids is an important property to judge the stability of a fatty acid film as the organic molecules may evaporate from the surface. Investigations of the longevity of binary $\mathrm{C} 12$ and $\mathrm{C} 18$ films on aqueous subphases showed the $\mathrm{C} 18$ acid monolayer being 
Table 2. Properties of fatty acids related to monolayer formation and stability.

\begin{tabular}{lcccccc}
\hline & $\begin{array}{c}\text { Melting point } \\
{\left[{ }^{\circ} \mathrm{C}\right]}\end{array}$ & $\begin{array}{c}\text { Vapor pressure } \\
\text { at } 25^{\circ} \mathrm{C}[\mathrm{Pa}]^{\mathrm{b}}\end{array}$ & $\begin{array}{c}\text { Solubility at } 20^{\circ} \mathrm{C}^{\mathrm{e}} \\
{[\text { weight } \%]}\end{array}$ & $p K_{\mathrm{a}}^{\mathrm{f}, \mathrm{g}, \mathrm{h}}$ & $\begin{array}{c}\mathrm{ESP} \text { at } 23^{\circ} \mathrm{C}^{\mathrm{i}} \\
{\left[\mathrm{mN} \mathrm{m}^{-1}\right]}\end{array}$ & $\begin{array}{c}F_{j} \text { at } 23^{\circ} \mathrm{C}^{\mathrm{i}} \\
{\left[\mathrm{mN} \mathrm{m}^{-1}\right]}\end{array}$ \\
\hline $\mathrm{C} 9$ & 12 & $\left(8 \times 10^{-2}\right)^{\mathrm{b}, \mathrm{d}}\left(1 \times 10^{-1}\right)^{\mathrm{c}, \mathrm{d}}$ & 0.0284 & & & \\
$\mathrm{C} 12$ & 44 & $\left(4 \times 10^{-3}\right)^{\mathrm{b}, \mathrm{d}}\left(3 \times 10^{-3}\right)^{\mathrm{c}, \mathrm{d}}$ & 0.0055 & 7.5 & 23.4 & 43.5 \\
$\mathrm{C} 14$ & 58 & $2.0 \times 10^{-4 \mathrm{~b}} 3.2 \times 10^{-4 \mathrm{c}}$ & 0.0020 & $8.1-8.2$ & 16.5 & 18 \\
$\mathrm{C} 15$ & 51 & $1.1 \times 10^{-4 \mathrm{~b}} 1.8 \times 10^{-4 \mathrm{c}}$ & 0.0012 & & 21.0 & 6.2 \\
$\mathrm{C} 16$ & 63 & $1.1 \times 10^{-5 \mathrm{~b}} 2.7 \times 10^{-5 \mathrm{c}}$ & 0.00072 & $8.6-8.8$ & 11.8 & $\approx 0$ \\
C18 & $69-71$ & $5.6 \times 10^{-7 \mathrm{~b}} 2.8 \times 10^{-6 \mathrm{c}}$ & 0.00029 & 10.15 & 3.7 & $\approx 0$ \\
Oleic acid & 16 & & & 9.85 & 31 & 100 \\
\hline
\end{tabular}

a (Römpp-online, 2006)

b (Chattopadhyay and Ziemann, 2005)

c (Tao and McMurry, 1989)

$\mathrm{d}$ The data given in brackets are extrapolated values from the measurements of the higher homologue fatty acids (C13-C18)

e (Handbook-of-Chemistry-and-Physics, 2006)

${ }^{\mathrm{f}} p K_{\mathrm{a}}$ of fatty acid in a monolayer on water

$\mathrm{g}$ (Kanicky et al., 2000)

h (Kanicky and Shah, 2002)

${ }^{\mathrm{i}}$ ESP: Equilibrium spreading pressure; $F_{j}$ : Film pressure of the transition from liquid expanded to liquid condensed film on water at $23^{\circ} \mathrm{C}$ (Seidl, 2000; Kellner et al., 1978)

stable over at least $16 \mathrm{~h}$, whereas they showed a significant loss $(\approx 50 \%)$ of the $\mathrm{C} 12$ acid either due to evaporation or solubilisation in the subphase after $10 \mathrm{~min}$ of storage (Gilman et al., 2004). In our experimental system the fatty acid coated aerosol travel $1 \mathrm{~min}$ before they are exposed to $\mathrm{HNO}_{3}(\mathrm{~g})$ in the reactor. Therefore, for the $\mathrm{C} 12$ compound, we can assume that it was stable during the short time scale of the experiment, while for $\mathrm{C} 9$ we might have lost a fraction due to evaporation.

The "equilibrium spreading pressure (ESP)" is the film pressure exhibited by an excess bulk phase on the monolayer films of a specific surfactant or in other words the film pressure, at which the polar groups of the surfactant film detach from the surface to form a bulk phase (a liquid lense, a solid structure or multilayers) in equilibrium with the surface film (Harkins and Boyd, 1941; Seidl, 2000; Gaines, 1966; Boyd, 1958). In the temperature range typical for the atmosphere, the ESP is a linear function of the temperature and the data collected in the fatty-acid-monolayer-model by Seidl (2000) is used calculate the ESP for different fatty acids at the experimental temperature $\left(23^{\circ} \mathrm{C}\right)$. All compounds exhibiting an ESP $>0 \mathrm{mN} \mathrm{m}^{-1}$ spontaneously spread over the aqueous surface, when coming in contact with water and form a selfassembled monolayer. As shown in Table 2 all fatty acids investigated here do form self-assembled monolayers at the experimental temperature. However, for higher homologue saturated fatty acids $(>\mathrm{C} 20)$ no spontaneous spreading on the aerosol surface is expected. As can be seen in Figs. 4 and 5 the formation of a monolayer of a fatty acid does not necessarily hinder the uptake of gaseous nitric acid. Monolayers of $\mathrm{C} 9, \mathrm{C} 12$ or oleic acids are apparently not capable to slow down the uptake of nitric acid even in presence of an excess bulk phase, which exhibits a significant pressure on the films. Therefore structural differences between the films formed by these compounds and those formed from $\mathrm{C} 15$ and $\mathrm{C} 18$ must exist. These differences are discussed here by means of the monolayer phase diagrams (Harkins and Boyd, 1941; Seidl, 2000; Kellner et al., 1978; Langmuir, 1917, 1933) of the individual compounds at the experimental temperature of $23^{\circ} \mathrm{C}$ (see Fig. 7). The phase diagrams are constructed as described by Seidl (2000). The phase diagram of the $\mathrm{C} 15$ acid shows most of the typical features of such phase diagrams and is used to explain the diagrams. The C15 monolayer is in the liquid expanded state at film pressures from close to zero up to $6 \mathrm{mN} \mathrm{m}^{-1}$ (Langmuir, 1933). The model understanding of this phase is that the fatty acid molecules exist in a densely packed layer with the acid group directed towards the aqueous surface, but the alkyl chains are likely neither straight nor parallel to the neighbouring alkyl chains. A molecule covers a surface area typically $2-3$ times as large as its axial molecular diameter. The expanded film can be compressed up to a film pressure $F j$. At this critical film pressure $F j$ $\left(6.2 \mathrm{mN} \mathrm{m}^{-1}\right.$ for $\mathrm{C} 15$ at $\left.23^{\circ} \mathrm{C}\right)$ the discontinuity in the molecular area vs. pressure diagram indicates a phase transition. The critical pressures $F j$ and their temperature dependencies have been compiled (Kellner et al., 1978; Seidl, 2000) for the fatty acids discussed here and are shown in Table 2. At $F j$ a transition region between the liquid expanded and the liquid condensed state starts, in which increasingly fatty acid clusters (micelles) are formed on the aqueous surface, 
which represent already the condensed state of the film, until the monolayer gets completely to the liquid condensed state (Langmuir, 1933; Gaines, 1966). In the liquid condensed state the alkyl chains are thought to be in parallel order and the surface area covered by a molecule approaches the axial molecular diameter of the fatty acid molecule. From the phase diagrams of the fatty acids shown in Fig. 7, we conclude that at the ESP, i.e. in presence of an excess amount of the fatty acids, films formed by $\mathrm{C} 15$ and $\mathrm{C} 18$ fatty acids are in the liquid condensed state. This hardly compressible, ordered film structure appears to effectively hinder the uptake of $\mathrm{HNO}_{3}(\mathrm{~g})$. In contrast, the monolayers formed by $\mathrm{C} 12, \mathrm{C} 9$ or oleic acid are in the liquid expanded state and these less ordered, more compressible films are apparently not capable to hinder $\mathrm{HNO}_{3}(\mathrm{~g})$-uptake. The dependence of ESP and $F j$ on the chain length of saturated fatty acids (Table 2) shows that at $23^{\circ} \mathrm{C}$ saturated fatty acids with chain lengths $>\mathrm{C} 15$ exhibit a sufficiently high ESP to form a liquid condensed film, whereas for shorter fatty acids the ESP does not reach the phase transition pressure $F j$. Therefore, only monolayers of linear, saturated fatty acids with chain lengths above C14 are expected to hinder the uptake of $\mathrm{HNO}_{3}(\mathrm{~g})$. But among these are palmitic (C16) and stearic (C18) acid, which are the most common fatty acids in biological membrane lipids. For $\mathrm{C} 18$ and $\mathrm{C} 15$ coatings consisting of sufficient amounts to ensure a complete monolayer ( $>4 \mathrm{~nm}$ on dry aerosol) a deactivation of the aerosol reactivity by a factor of 3-10 and $50 \pm 15$ was obtained, respectively. The stronger deactivation by the $\mathrm{C} 15$ coating may be related to its more compressed monolayers due to its higher equilibrium spreading pressure. Similar to the shorter chain homologue fatty acids also nonlinear fatty acids such as oleic acid (containing a cis double bond) are incapable to form a condensed film and cannot lower the uptake of $\mathrm{HNO}_{3}(\mathrm{~g})$. Similarly, humic acids used here as a model for a mixture of water soluble surfactants do not form structured monolayers and have no measurable effect on the reaction.

A number of studies have addressed the effects of organic coatings on the phase transfer of other atmospherically relevant molecules. Since long, evaporation of water through monolayers of a variety of surfactants (Rosano and Lamer, 1956; Garrett, 1971) had been studied, showing that surfactants in expanded monolayers did not reduce water evaporation, in contrast to surfactants in condensed monolayer states. This was also confirmed for butanol films on supercooled sulfuric acid that appeared to be porous to water (Lawrence et al., 2005). Similarly, Xiong et al. (1998) observed that a $\mathrm{C} 18$ coating reduced the hydroscopic growth rate of sulphuric acid aerosol, while coatings of oleic acid had no effect, even though they also saw an inhibition by the C12 acid, which should not have been in a condensed monolayer state. The uptake of gaseous ammonia to sulphuric acid droplets was shown to be strongly hindered by coatings of hexadecane or hexadecanol (Däumer et al., 1992). A monolayer of these compounds was found to reduce the uptake

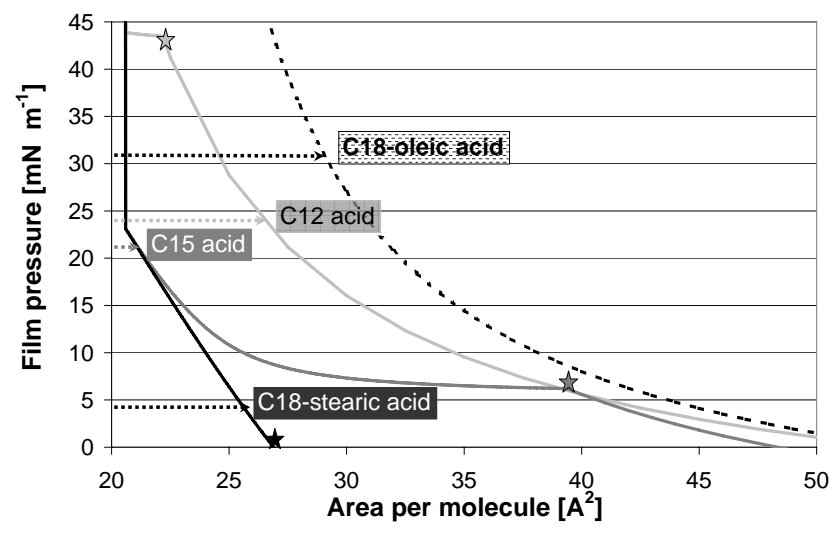

Fig. 7. Phase diagrams for monolayers of lauric acid (C12), pentadecanoic acid (C15), stearic acid (C18) and oleic acid (C18:1) at $23^{\circ} \mathrm{C}$ according to the model of Seidl (2000). The diagram correlates the average surface area of a single molecule in the monolayer with the film pressure. For $\mathrm{C} 12, \mathrm{C} 15$ and $\mathrm{C} 18$ the phase transition between expanded and condensed monolayers is within the range of this plot and is marked by a star. The dotted arrows indicate the spreading pressure of an excess bulk phase of the individual fatty acids. This quantity determines the film pressure in presence of an excess amount of the n-alkanoic acids.

rate by more than 90\%, 2-3 monolayers were sufficient for a nearly complete suppression of the heterogeneous reaction. The same experiments with coatings produced from terpenes indicated surprisingly that $\alpha$-pinene films (thickness $\approx 3 \mathrm{~nm}$ ) form an effective barrier for ammonia, whereas limonene and camphene were only weakly lowering the uptake. The uptake of $\mathrm{H}_{2} \mathrm{SO}_{4}$ on solid $\mathrm{NaCl}$ particles was reduced by a thin stearic acid layer (some nm thick) by a factor of three, but surprisingly a thicker film was a less effective barrier (Jefferson et al., 1997). The uptake of $\mathrm{HCl}$ and $\mathrm{HBr}$ was either slightly enhanced or slightly impeded by a hexanol film on concentrated sulphuric acid, depending on how densely packed the film was (Glass et al., 2006). The enhancement was suggested to be due to additional interactions of the alcohol headgroup with $\mathrm{HBr}$ and $\mathrm{HCl}$ in the interfacial region. Similar to the results presented here, the uptake of acetic acid through monolayers of saturated $\mathrm{C} 18$ to $\mathrm{C} 30$ alcohols into an aqueous subphase was strongly reduced, while it was not affected by the unsaturated C18 acid oleic acid (Gilman and Vaida, 2006), which was also related to the pressure area isotherms of these surfactants.

There has been only one study with $\mathrm{HNO}_{3}$ into this aspect (Clifford et al., 2007), which shows no inhibition of the overall uptake by a monolayer of octanol, even though some suppression of transient acidity probed by a surface sensitive $\mathrm{pH}$ indicator was observed. When comparing our data to these other related reports, we may conclude that in case of expanded monolayers, sufficient amounts of aqueous phase is still exposed at the particle - air interface to allow $\mathrm{HNO}_{3}$ to be taken up and dissociate (and acid displacement to occur), 
while on the condensed monolayers, $\mathrm{HNO}_{3}$ adsorbs onto a mostly hydrophobic surface, from which it rather desorbs than enters into the liquid phase. We have not found evidence for increased uptake for the $\mathrm{C} 9$ or $\mathrm{C} 12$ acids, as was observed for $\mathrm{HBr}$ and $\mathrm{HCl}$ in presence of smaller alcohols (Glass et al., 2006).

Compared to these examples of trace gas molecules with a strong affinity to water and acid base equilibrium driving the uptake, the effect of organic coatings on the hydrolysis of dinitrogen pentoxide $\left(\mathrm{N}_{2} \mathrm{O}_{5}\right)$ is somewhat different. The uptake of $\mathrm{N}_{2} \mathrm{O}_{5}$ was impeded by butanol and hexanol films on sulphuric acid (Park et al., 2007), by sodium dodecyl sulphate on $\mathrm{NaCl}$ or natural sea water solutions already at submonolayer coverages (McNeill et al., 2006), by hexanoic acid on aqueous sea salt particles (Thornton and Abbatt, 2005), by ozonolysis products of $\alpha$-pinene on aqueous ammonium sulphate particles (Folkers et al., 2003) and by humic acids representing an unstructured surfactant film (Badger et al., 2006). Obviously, the hydrolysis of the much less soluble $\mathrm{N}_{2} \mathrm{O}_{5}$ may already be affected by less densely packed organic coatings, but might also be more sensitive to the water activity of the mixed aqueous particles. In the most recent study, Cosman et al. (2008) found effects that are related to what we have observed for $\mathrm{HNO}_{3}$ in that a monolayer of octadecanol was strongly inhibiting the uptake of $\mathrm{N}_{2} \mathrm{O}_{5}$, while the addition of a branched surfactant strongly decreased the resistance to $\mathrm{N}_{2} \mathrm{O}_{5}$ uptake again.

\section{Atmospheric implications}

This study shows that specific coatings of long chain fatty acids ( $\mathrm{C} 15$ and $\mathrm{C} 18)$ in monolayer dimensions can create a significant resistance to the uptake of $\mathrm{HNO}_{3}(\mathrm{~g})$ into aqueous aerosol, while coatings of shorter chain fatty acids (C9 and $\mathrm{C} 12$ ) or high mass fractions of water soluble organic compounds (such as humic acid) do not exhibit a measurable impact on the uptake. While the effects observed here are similar to those for other acids, they seem to be somewhat different for other species (such as $\mathrm{N}_{2} \mathrm{O}_{5}$ ), which exhibit different behaviour at the interface. The dominance of long chain fatty acids as surfactants on marine aerosol has been observed in field measurements, but under environmental conditions it is questionable if these compounds would be able to discriminate other organic impurities from the aerosol surface to form a similarly impermeable layer as under the experimental conditions. The water evaporation through mixed films consisting of both, long chain and shorter chain surfactants has been shown to have a resistance in between those of the single component layers (Rosano and Lamer, 1956), as also discussed by Gilman and Vaida (2006). Therefore, we suspect that on real marine aerosol, the effects on $\mathrm{HNO}_{3}$ uptake might be less pronounced than observed in this model study.
Acknowledgements. We would like to thank M. Birrer for technical support and S. Brütsch for the ion chromatography analysis. We also greatly acknowledge the staff of the PSI accelerator facility for their efforts to provide a stable proton beam. We appreciate financial support by the Swiss National Science Foundation (grant no. 200020-100275).

Edited by: T. Hoffmann

\section{References}

Abbatt, J. P. D. and Waschewsky, G. C. G.: Heterogeneous interactions of $\mathrm{HOBr}, \mathrm{HNO}_{3}, \mathrm{O}_{3}$, and $\mathrm{NO}_{2}$ with deliquescent $\mathrm{NaCl}$ aerosols at room temperature, J. Phys. Chem. A, 102, 37193725, 1998.

Alves, C., Carvalho, A., and Pio, C.: Mass balance of organic carbon fractions in atmospheric aerosols, J. Geophys. Res., 107(D21), 8345, doi:10.1029/2001JD000616, 2002.

Ammann, M.: Using ${ }^{13} \mathrm{~N}$ as tracer in heterogeneous atmospheric chemistry experiments, Radiochim. Acta, 89, 831-838, 2001.

Badger, C. L., Griffiths, P. T., George, I., Abbatt, J. P. D., and Cox, R. A.: Reactive uptake of $\mathrm{N}_{2} \mathrm{O}_{5}$ by aerosol particles containing mixtures of humic acid and ammonium sulfate, J. Phys. Chem., 110, 6986-6994, 2006.

Barger, W. R. and Garrett, W. D.: Surface-active organic material in air over the mediterranean and over the eastern equatorial pacific, J. Geophys. Res., 81, 3151-3157, 1976.

Beichert, P. and Finlayson-Pitts, B. J.: Knudsen cell studies of the uptake of gaseous $\mathrm{HNO}_{3}$ and other oxides of nitrogen on solid $\mathrm{NaCl}$ : The role of surface-adsorbed water, J. Phys. Chem., 100, 15 218-15 228, 1996.

Blanchard, D. C.: Sea-to-air transport of surface active material, Science, 146, 396-397, 1964.

Boyd, G. E.: Energy relations in monolayer formation - the spreading of long-chain fatty acids on aqueous surfaces, J. Phys. Chem., 62, 536-541, 1958.

Brimblecombe, P. and Clegg, S. L.: The solubility and behavior of acid gases in the marine aerosol, J. Atmos. Chem., 7, 1-18, 1988.

Cappiello, A., De Simoni, E., Fiorucci, C., Mangani, F., Palma, P., Trufelli, H., Decesari, S., Facchini, M. C., and Fuzzi, S.: Molecular characterization of the water-soluble organic compounds in fogwater by ESIMS/MS, Environ. Sci. Technol., 37, 1229-1240, 2003.

Cavalli, F., Facchini, M. C., Decesari, S., Mircea, M., Emblico, L., Fuzzi, S., Ceburnis, D., Yoon, Y. J., O’Dowd, C. D., Putaud, J. P., and Dell'Acqua, A.: Advances in characterization of size-resolved organic matter in marine aerosol over the north atlantic, J. Geophys. Res.-Atmos., 109, D24215, doi:10.1029/2004JD005137, 2004.

Clifford, D., Bartels-Rausch, T., and Donaldson, D. J.: Suppression of aqueous surface hydrolysis by monolayers of short chain organic amphiphiles, Phys. Chem. Chem. Phys., 9, 1362-1369, 2007.

Cosman, L. M. and Bertram, A. K.: Reactive Uptake of $\mathrm{N}_{2} \mathrm{O}_{5}$ on Aqueous $\mathrm{H}_{2} \mathrm{SO}_{4}$ Solutions Coated with 1-Component and 2-Component Monolayers, J. Phys. Chem. A, 112, 4625-4635, 2008.

Chattopadhyay, S. and Ziemann, P. J.: Vapor pressures of substituted and unsubstituted monocarboxylic and dicarboxylic acids 
measured using an improved thermal desorption particle beam mass spectrometry method, Aerosol Sci. Tech., 39, 1085-1100, 2005.

Chuang, P. Y.: Measurement of the timescale of hygroscopic growth for atmospheric aerosols, J. Geophys. Res., 108(D9), 4282, doi:10.1029/2002JD002757, 2003.

Däumer, B., Niessner, R., and Klockow, D.: Laboratory studies of the influence of thin organic films on the neutralization reaction of $\mathrm{H}_{2} \mathrm{SO}_{4}$ aerosol with ammonia, J. Aerosol Sci., 23, 315-325, 1992.

Davies, J. A. and Cox, R. A.: Kinetics of the heterogeneous reaction of $\mathrm{HNO}_{3}$ with $\mathrm{NaCl}$ : Effect of water vapor, J. Phys. Chem. A, 102, 7631-7642, 1998.

de Moraes, S. L. and Rezende, M. O. O.: Determination of the critical micelle concentration of humic acids by spectroscopy and conductimetric measurements, Quim. Nova, 27, 701-705, 2004.

Donaldson, D. J. and Vaida, V.: The influence of organic films at the air-aqueous boundary on atmospheric processes, Chem. Rev., 106, 1445-1461, 2006.

Ellison, G. B., Tuck, A. F., and Vaida, V.: Atmospheric processing of organic aerosols, J. Geophys. Res., 104, 11 633-11 641, 1999.

Facchini, M. C., Decesari, S., Mircea, M., Fuzzi, S., and Loglio, G.: Surface tension of atmospheric wet aerosol and cloud/fog droplets in relation to their organic carbon content and chemical composition, Atmos. Environ., 34, 4853-4857, 2000.

Folkers, M., Mentel, T. F., and Wahner, A.: Influence of an organic coating on the reactivity of aqueous aerosols probed by the heterogeneous hydrolysis of $\mathrm{N}_{2} \mathrm{O}_{5}$, Geophys. Res. Lett., 30(12), 1644, doi:10.1029/2003GL017168, 2003.

Fraser, M. P., Cass, G. R., and Simoneit, B. R. T.: Air quality model evaluation data for organics, 6. C-3-C-24 organic acids, Environ. Sci. Technol., 37, 446-453, 2003.

Gaines, G. L.: Insoluble monolayers at liquid-gas interfaces, Interscience monographs on physical chemistry, edited by: Prigogine, I., Interscience Publishers, New York, 1966.

Gard, E. E., Kleeman, M. J., Gross, D. S., Hughes, L. S., Allen, J. O., Morrical, B. D., Fergenson, D. P., Dienes, T., Galli, M. E., Johnson, R. J., Cass, G. R., and Prather, K. A.: Direct observation of heterogeneous chemistry in the atmosphere, Science, 279, 1184-1187, 1998.

Garrett, W. D.: Retardation of water drop evaporation with monomolecular surface films, J. Atmos. Sci., 28, 816-819, 1971.

Gelencser, A., Meszaros, T., Blazso, M., Kiss, G., Krivacsy, Z., Molnar, A., and Meszaros, E.: Structural characterisation of organic matter in fine tropospheric aerosol by pyrolysis-gas chromatography-mass spectrometry, J. Atmos. Chem., 37, 173$183,2000$.

Gelencser, A., Hoffer, A., Kiss, G., Tombacz, E., Kurdi, R., and Bencze, L.: In-situ formation of light-absorbing organic matter in cloud water, J. Atmos. Chem., 45, 25-33, 2003.

Ghosal, S. and Hemminger, J. C.: Surface adsorbed water on $\mathrm{NaCl}$ and its effect on nitric acid reactivity with $\mathrm{NaCl}$ powders, J. Phys. Chem. B, 108, 14 102-14 108, 2004.

Gill, P. S., Graedel, T. E., and Weschler, C. J.: Organic films on atmospheric aerosol-particles, fog droplets, cloud droplets, raindrops, and snowflakes, Rev. Geophys., 21, 903-920, 1983.

Gilman, J. B., Eliason, T. L., Fast, A., and Vaida, V.: Selectivity and stability of organic films at the air-aqueous interface, J. Colloid Interf. Sci., 280, 234-243, 2004.
Gilman, J. B. and Vaida, V.: Permeability of acetic acid through organic films at the air-aqueous interface, J. Phys. Chem. A, 110, 7581-7587, 2006.

Glass, S. V., Park, S. C., and Nathanson, G. M.: Evaporation of water and uptake of $\mathrm{HCl}$ and $\mathrm{HBr}$ through hexanol films at the surface of supercooled sulfuric acid, J. Phys. Chem. A, 110, 75937601, 2006.

Graham, B., Mayol-Bracero, O. L., Guyon, P., Roberts, G. C., Decesari, S., Facchini, M. C., Artaxo, P., Maenhaut, W., Koll, P., and Andreae, M. O.: Water-soluble organic compounds in biomass burning aerosols over amazonia - 1. Characterization by NMR and GC-MS, J. Geophys. Res., 107(D20), 8047, doi:10.1029/2001JD000336, 2002.

Guimbaud, C., Arens, F., Gutzwiller, L., Gäggeler, H. W., and Ammann, M.: Uptake of $\mathrm{HNO}_{3}$ to deliquescent sea-salt particles: A study using the short-lived radioactive isotope tracer N-13, Atmos. Chem. Phys., 2, 249-257, 2002, http://www.atmos-chem-phys.net/2/249/2002/.

Hansson, H. C., Rood, M. J., Koloutsou-Vakakis, S., Hameri, K., Orsini, D., and Wiedensohler, A.: $\mathrm{NaCl}$ aerosol particle hygroscopicity dependence on mixing with organic compounds, J. Atmos. Chem., 31, 321-346, 1998.

Harkins, W. D. and Boyd, E.: The states of monolayers, J. Phys. Chem., 45, 20-45, 1941.

Jang, M. S., Czoschke, N. M., Lee, S., and Kamens, R. M.: Heterogeneous atmospheric aerosol production by acid-catalyzed particle-phase reactions, Science, 298, 814-817, 2002.

Jang, M. S., Carroll, B., Chandramouli, B., and Kamens, R. M.: Particle growth by acid-catalyzed heterogeneous reactions of organic carbonyls on preexisting aerosols, Environ. Sci. Technol., 37, 3828-3837, 2003.

Jefferson, A., Eisele, F. L., Ziemann, P. J., Weber, R. J., Marti, J. J., and McMurry, P. H.: Measurements of the $\mathrm{H}_{2} \mathrm{SO}_{4}$ mass accommodation coefficient onto polydisperse aerosol, J. Geophys. Res., 102, 19021-19028, 1997.

Kalberer, M., Ammann, M., Arens, F., Gaggeler, H. W., and Baltensperger, U.: Heterogeneous formation of nitrous acid (HONO) on soot aerosol particles, J. Geophys. Res., 104, 13 825-13 832, 1999.

Kalberer, M., Paulsen, D., Sax, M., Steinbacher, M., Dommen, J., Prevot, A. S. H., Fisseha, R., Weingartner, E., Frankevich, V., Zenobi, R., and Baltensperger, U.: Identification of polymers as major components of atmospheric organic aerosols, Science, 303, 1659-1662, 2004.

Kanicky, J. R., Poniatowski, A. F., Mehta, N. R., and Shah, D. O.: Cooperativity among molecules at interfaces in relation to various technological processes: Effect of chain length on the $\mathrm{pk}(\mathrm{a})$ of fatty acid salt solutions, Langmuir, 16, 172-177, 2000.

Kanicky, J. R. and Shah, D. O.: Effect of degree, type, and position of unsaturation on the $\mathrm{pk}(\mathrm{a})$ of long-chain fatty acids, J. Colloid Interf. Sci., 256, 201-207, 2002.

Kellner, B. M. J., Mullerlandau, F., and Cadenhead, D. A.: Temperature-dependence characterization of insoluble films at air-water-interface, J. Colloid Interf. Sci., 66, 597-601, 1978.

Krivacsy, Z., Kiss, G., Varga, B., Galambos, I., Sarvari, Z., Gelencser, A., Molnar, A., Fuzzi, S., Facchini, M. C., Zappoli, S., Andracchio, A., Alsberg, T., Hansson, H. C., and Persson, L.: Study of humic-like substances in fog and interstitial aerosol by size-exclusion chromatography and capillary electrophoresis, 
Atmos. Environ., 34, 4273-4281, 2000.

Langmuir, I.: The constitution and fundamental properties of solids and liquids. II. Liquids., J. Am. Chem. Soc., 39, 1848-1906, 1917.

Langmuir, I.: Oil lenses on water and the nature of monomolecular expanded films, J. Chem. Phys., 1, 756-776, 1933.

Latif, M. T. and Brimblecombe, P.: Surfactants in atmospheric aerosols, Environ. Sci. Technol., 38, 6501-6506, 2004.

Lawrence, J. R., Glass, S. V., and Nathanson, G. M.: Evaporation of Water through Butanol Films at the Surface of Supercooled Sulfuric Acid, J. Phys. Chem. A, 109, 7449-7457, 2005.

Levaggi, D. A., Siu, W., Feldstein, M., and Kothny, E. L.: Quantitative separation of nitric-oxide from nitrogen-dioxide at atmospheric concentration ranges, Environ. Sci. Technol., 6, 250-252, 1972.

Lide, D.R.(ed.): Handbook of chemistry and physics, 86th ed., CRC Press, Cleveland, 2006.

Liu, Y., Cain, J. P., Wang, H., and Laskin, A.: Kinetic study of heterogeneous reaction of deliquesced $\mathrm{NaCl}$ particles with gaseous $\mathrm{HNO}_{3}$ using particle-on-substrate stagnation flow reactor approach, J. Phys. Chem. A, 111, 10 026-10 043, 2007.

Ma, J., Jiang, J., Pang, S., and Guo, J.: Adsorptive fractionation of humic acid at air-water interfaces, Environ. Sci. Technol., 41, 4959-4964, 2007.

Mayol-Bracero, O. L., Guyon, P., Graham, B., Roberts, G., Andreae, M. O., Decesari, S., Facchini, M. C., Fuzzi, S., and Artaxo, P.: Water-soluble organic compounds in biomass burning aerosols over amazonia -2 . Apportionment of the chemical composition and importance of the polyacidic fraction, J. Geophys. Res., 107(D20), 8091, doi:10.1029/2001JD000522, 2002.

McNeill, V. F., Patterson, J., Wolfe, G. M., and Thornton, J. A.: The effect of varying levels of surfactant on the reactive uptake of $\mathrm{N}_{2} \mathrm{O}_{5}$ to aqueous aerosol, Atmos. Chem. Phys., 6, 1635-1644, 2006,

http://www.atmos-chem-phys.net/6/1635/2006/.

Middlebrook, A. M., Murphy, D. M., and Thomson, D. S.: Observations of organic material in individual marine particles at cape grim during the first aerosol characterization experiment (ACE 1), J. Geophys. Res., 103, 16475-16 483, 1998.

Mochida, M., Kitamori, Y., Kawamura, K., Nojiri, Y., and Suzuki, K.: Fatty acids in the marine atmosphere: Factors governing their concentrations and evaluation of organic films on sea-salt particles, J. Geophys. Res., 107, 4325, doi:10.1029/2001JD001278, 2002.

Mochida, M., Kawamura, K., Umemoto, N., Kobayashi, M., Matsunaga, S., Lim, H. J., Turpin, B. J., Bates, T. S., and Simoneit, B. R. T.: Spatial distributions of oxygenated organic compounds (dicarboxylic acids, fatty acids, and levoglucosan) in marine aerosols over the western pacific and off the coast of East Asia: Continental outflow of organic aerosols during the ACE-Asia campaign, Geophys. Res., 108(D23), 8638, doi:10.1029/2002JD003249, 2003.

Mukai, H. and Ambe, Y.: Characterization of a humic acid-like brown substance in airborne particulate matter and tentative identification of its origin, Atmos. Environ., 20, 813-819, 1986.

Nozière, B. and Esteve, W.: Organic reactions increasing the absorption index of atmospheric sulfuric acid aerosols, Geophys. Res. Lett., 32, L03812, doi:10.1029/2004GL021942, 2005.

O’Dowd, C. D., Becker, E., and Kulmala, M.: Mid-latitude north- atlantic aerosol characteristics in clean and polluted air, Atmos. Res., 58, 167-185, 2001.

O’Dowd, C. D., Facchini, M. C., Cavalli, F., Ceburnis, D., Mircea, M., Decesari, S., Fuzzi, S., Yoon, Y. J., and Putaud, J. P.: Biogenically driven organic contribution to marine aerosol, Nature, 431, 676-680, 2004.

Park, S. C., Burden, D. K., and Nathanson, G. M.: The inhibition of $\mathrm{N}_{2} \mathrm{O}_{5}$ hydrolysis in sulfuric acid by 1-butanol and 1-hexanol surfactant coatings, J. Phys. Chem. A, 111, 2921-2929, 2007.

Rogak, S. N., Baltensperger, U., and Flagan, R. C.: Measurement of mass-transfer to agglomerate aerosols, Aerosol Sci. Tech., 14, 447-458, 1991.

Romano, J. C.: Sea-surface slick occurrence in the open sea (mediterranean, red sea, indian ocean) in relation to wind speed, Deep-Sea Res., 43, 411-423, 1996.

Römpp: available at:www.roempp.com, 2006.

Rosano, H. L. and Lamer, V. K.: The rate of evaporation of water through monolayers of esters, acids and alcohols, J. Phys. Chem., 60, 348-353, 1956.

Rossi, M. J.: Heterogeneous reactions on salts, Chem. Rev., 103, 4823-4882, 2003.

Rudich, Y.: Laboratory perspectives on the chemical transformations of organic matter in atmospheric particles, Chem. Rev., 103, 5097-5124, 2003.

Saul, T. D., Tolocka, M. P., and Johnston, M. V.: Reactive uptake of nitric acid onto sodium chloride aerosols across a wide range of humidities, J. Phys. Chem. A, 110, 7614-7620, 2006.

Seidl, W.: Model for a surface film of fatty acids on rain water and aerosol particles, Atmos. Environ., 34, 4917-4932, 2000.

Sicre, M. A., Gagosian, R. B., and Peltzer, E. T.: Evaluation of the atmospheric transport of marine-derived particles using longchain unsaturated-ketones, J. Geophys. Res., 95, 1789-1795, 1990.

Spokes, L. J., Yeatman, S. G., Cornell, S. E., and Jickells, T. D.: Nitrogen deposition to the eastern atlantic ocean. The importance of south-easterly flow, Tellus B, 52, 37-49, 2000.

Tabazadeh, A.: Organic aggregate formation in aerosols and its impact on the physicochemical properties of atmospheric particles, Atmos. Environ., 39, 5472-5480, 2005.

Tao, Y. and McMurry, P. H.: Vapor-pressures and surface freeenergies of C14-C18 monocarboxylic acids and C5-dicarboxylic and C6-dicarboxylic acids, Environ. Sci. Technol., 23, 15191523, 1989.

ten Brink, H. M.: Reactive uptake of $\mathrm{HNO}_{3}$ and $\mathrm{H}_{2} \mathrm{SO}_{4}$ in sea-salt $(\mathrm{NaCl})$ particles, J. Aerosol Sci., 29, 57-64, 1998.

Tervahattu, H., Juhanoja, J., and Kupiainen, K.: Identification of an organic coating on marine aerosol particles by TOF-SIMS, J. Geophys. Res., 107(D16), doi:10.1029/2001JD001403, 2002.

Thornton, J. A. and Abbatt, J. P. D.: $\mathrm{N}_{2} \mathrm{O}_{5}$ reaction on submicron sea salt aerosol: Kinetics, products, and the effect of surface active organics, J. Phys. Chem. A, 109, 10 004-10 012, 2005.

Tolocka, M. P., Saul, T. D., and Johnston, M. V.: Reactive uptake of nitric acid into aqueous sodium chloride droplets using realtime single-particle mass spectrometry, J. Phys. Chem. A, 108, 2659-2665, 2004.

Vlasenko, A., Sjogren, S., Weingartner, E., Gaggeler, H. W., and Ammann, A.: Generation of submicron arizona test dust aerosol: Chemical and hygroscopic properties, Aerosol Sci. Tech., 39, 452-460, 2005. 
Vlasenko, A., Sjogren, S., Weingartner, E., Stemmler, K., Gäggeler, H. W., and Ammann, M.: Effect of humidity on nitric acid uptake to mineral dust aerosol particles, Atmos. Chem. Phys., 6, 21472160, 2006,

http://www.atmos-chem-phys.net/6/2147/2006/.

Xiong, J. Q., Zhong, M. H., Fang, C. P., Chen, L. C., and Lippmann, M.: Influence of organic films on the hygroscopicity of ultrafine sulfuric acid aerosol, Environ. Sci. Technol., 32, 35363541,1998
Zappoli, S., Andracchio, A., Fuzzi, S., Facchini, M. C., Gelencser, A., Kiss, G., Krivacsy, Z., Molnar, A., Meszaros, E., Hansson, H. C., Rosman, K., and Zebuhr, Y.: Inorganic, organic and macromolecular components of fine aerosol in different areas of Europe in relation to their water solubility, Atmos. Environ., 33, 27332743, 1999. 